\section{Arkivoc}

Archive for

Organic Chemistry
The Free Internet Journal

for Organic Chemistry
Review

Arkivoc 2019, part ii, 114-143

\title{
Recent advances in selenium promoted or catalyzed electrophilic aminations of alkenes and alkynes
}

\author{
Martina Palomba, Francesca Mangiavacchi, and Francesca Marini* \\ Department of Pharmaceutical Sciences, University of Perugia, Via del Liceo, 1 - 06123 Perugia, Italy \\ Email: francesca.marini@unipg.it
}

Dedicated to Prof. Lorenzo Testaferri on the occasion of his $75^{\text {th }}$ birthday

Received 09-27-2019

Accepted 11-05-2019

Published on line 11-30-2019

\section{Abstract}

In the last decades, synthetic methods for the construction of carbon-nitrogen bonds rapidly grew, due to the important applications of amino compounds in fine chemicals, biological and pharmaceutical sciences. The aminoselenylations of alkenes and alkynes are versatile reactions that usually occur with high regio- and stereo-control under mild reaction conditions. Linear and cyclic compounds can be prepared with wide functional and structural diversity using stoichiometric or catalytic amounts of electrophilic selenium reagents. This review collects recent advances in this attractive and fruitful research field.

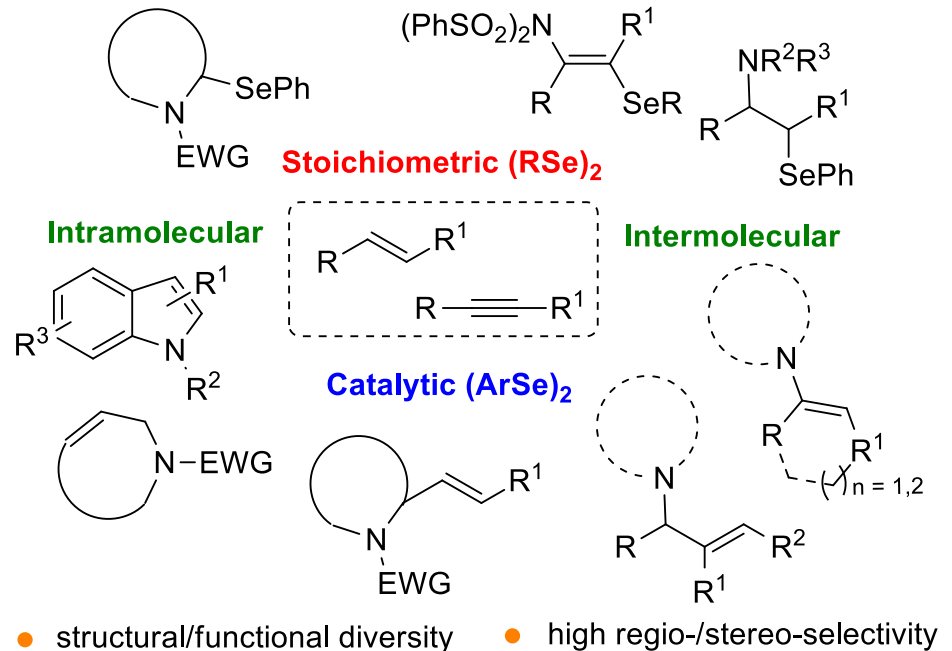

Keywords: Selenium, aminations, diorganyl diselenides, heterocycles, alkene functionalizations 


\section{Table of Contents}

1. Introduction

2. Intermolecular Aminoselenylations of C-C Double and Triple bonds

3. Intramolecular Aminoselenylations of C-C Double or Triple Bonds

4. Electrophilic Selenium-catalyzed Aminations of Alkenes

5. Conclusions

\section{Introduction}

Nitrogen containing molecules are fundamental structural motifs in natural products and biologically active compounds. The access to a diverse array of functionalized compounds is critical in drug discovery projects and also for this reason in the past few decades, operationally simple new methodologies for $\mathrm{C}-\mathrm{N}$ bond formation have been deeply investigated. In this field, the electrophilic seleno-functionalizations of carboncarbon multiple bonds ${ }^{1-8}$ offer interesting opportunities, also in consideration of the growing interest in the pharmacological and toxicological properties of selenium-containing compounds. ${ }^{8-14}$ The reaction of alkenes with commercial selenium electrophiles, such as $\mathrm{PhSeCl}, \mathrm{PhSeBr}$ or Phenylselenophthalimide (NPSP), has been deeply explored (Scheme 1). Other electrophilic reagents can be generated by oxidative cleavage of benchstable diselenides using inorganic or organic oxidants, typically persulfates or hypervalent iodine species.

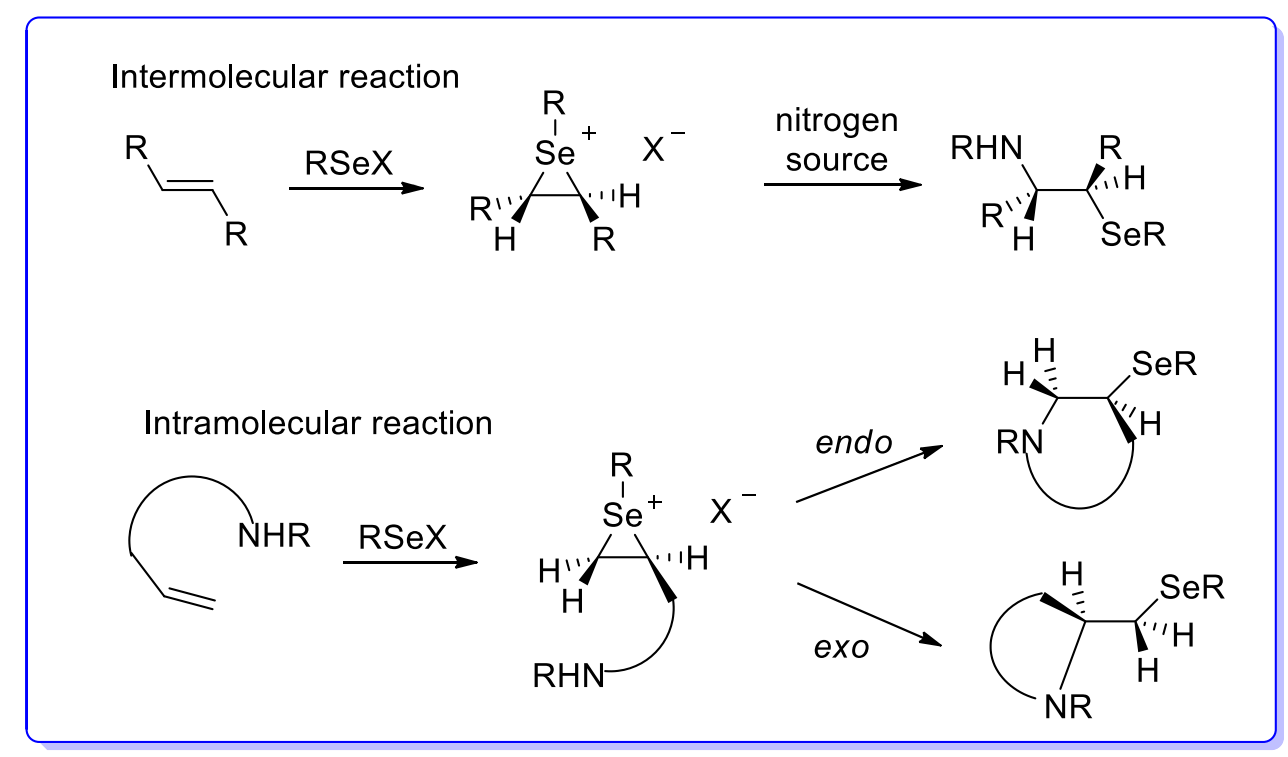

Scheme 1. Inter or intramolecular aminoselenylations of alkenes.

Mechanistically, the insertion of the selenium electrophile into the carbon-carbon unsaturated bond generates a cyclic seleniranium ion which is captured by the nucleophile with high regio- and stereo-control. The reaction can occur also intramolecularly, offering a powerful synthetic route to heterocycles. Since the selenium forms relatively weak $\sigma$-bonds, the incorporated selenium moiety can be used for further radical or ionic conversions leading to non selenium-containing substitution or elimination products. These reactions occur at a faster rate and under milder conditions than those of the corresponding sulfurated analogous. The 
seleno-functionalizations have developed rapidly over the past 30 years and have become a useful tool for the chemo-, regio-, stereo- and also enantio-selective synthesis of organic molecules. However, if seleniummediated $\mathrm{C}-\mathrm{O}$ bond forming reactions have been extensively studied, the examples of $\mathrm{C}-\mathrm{N}$ bond formation are relatively few. This survey will focus on recent advances in selenium-promoted or -catalyzed aminofunctionalizations of double and triple bonds covering the literature of the last 15 years. Representative previous works will be also discussed in order to illustrate the synthetic potential of the method.

\section{Intermolecular Aminoselenylations of C-C Double and Triple Bonds}

The amidoselenylation and the azidoselenylation of alkenes are typical approaches for the introduction of nitrogen-centered nucleophiles. The amidoselenylation of alkenes by treatment with $\mathrm{PhSeCl}$ in acetonitrile and water in the presence of trifluoromethane sulfonic acid was pioneered by Toshimitsu and Uemura in the 80s (Scheme 2, method a). ${ }^{15-16}$ These Ritter-type reactions proceed by the attack of the nitrogen atom of acetonitrile on the seleniranium ion to give an intermediate which undergoes hydrolysis. Similar reactions can be carried out with diverse nitriles, such as propionitrile, butyronitrile, and benzonitrile. $\mathrm{NH}_{2} \mathrm{CN}$ (Scheme 2 , method b) gave cyanamideselenylation products as the result of the nucleophilic attack on the seleniranium ion by the amino group, instead. ${ }^{17}$ Enantiomerically pure amidoselenylation products have been isolated from reactions carried out with a camphor-derived diselenide as the chiral selenium source. ${ }^{18}$

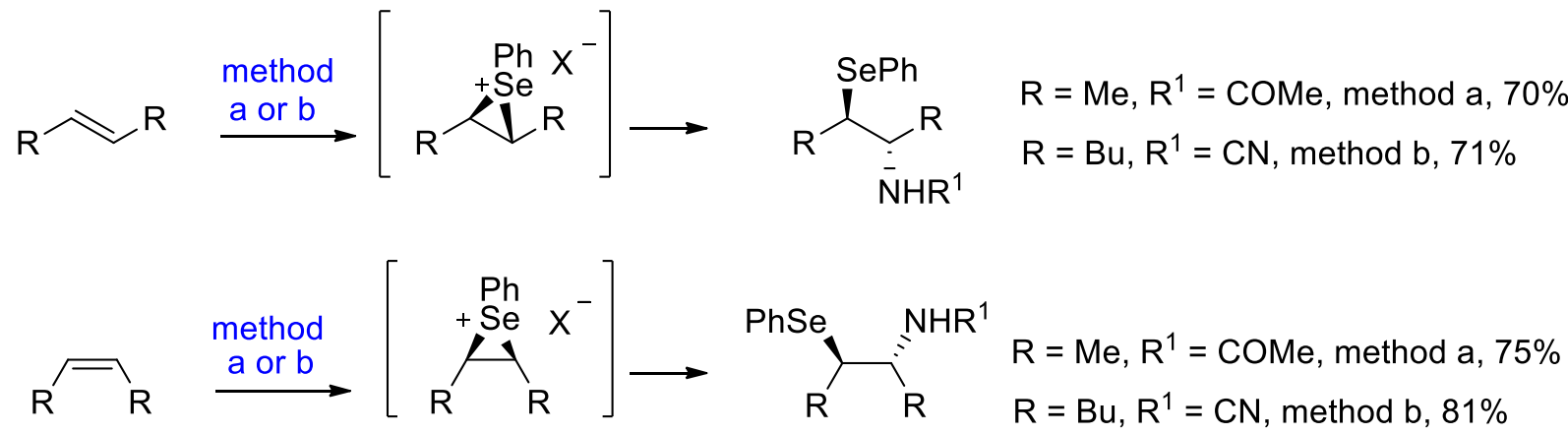
a. $\mathrm{PhSeCl}, \mathrm{CF}_{3} \mathrm{SO}_{3} \mathrm{H}, \mathrm{CH}_{3} \mathrm{CN}, \mathrm{H}_{2} \mathrm{O}$, reflux
b. NPSP, $p$ - $\mathrm{TsOH}, \mathrm{NH}_{2} \mathrm{CN}, \mathrm{CH}_{2} \mathrm{Cl}_{2}$, rt

Scheme 2. First aminoselenylations of alkenes.

The amidoselenylation of alkenes is the key step of cascade processes useful for the synthesis of diversely functionalized 4,5-dihydro-1,3-oxazoles (Scheme 3). ${ }^{19}$ In these protocols the electrophilic phenylselenyl sulfate, produced in situ by oxidation of the diphenyldiselenide with ammonium persulfate, reacts with an alkene in the presence of acetonitrile, $\mathrm{H}_{2} \mathrm{O}$ and $\mathrm{CF}_{3} \mathrm{SO}_{3} \mathrm{H}(\mathrm{TfOH})$, and generates the amido selenylation products. In the further steps the selenoacetamides are converted into selenonium ions and finally into the 4,5-dihydro-1,3-oxazole as an effect of an intramolecular nucleophilic substitution by the amidic oxygen. 2amino substituted-1,3-oxazoles were similarly formed from reactions with the cyanamide. The procedure was also adapted to the synthesis of the taxol side chain. ${ }^{20}$ 


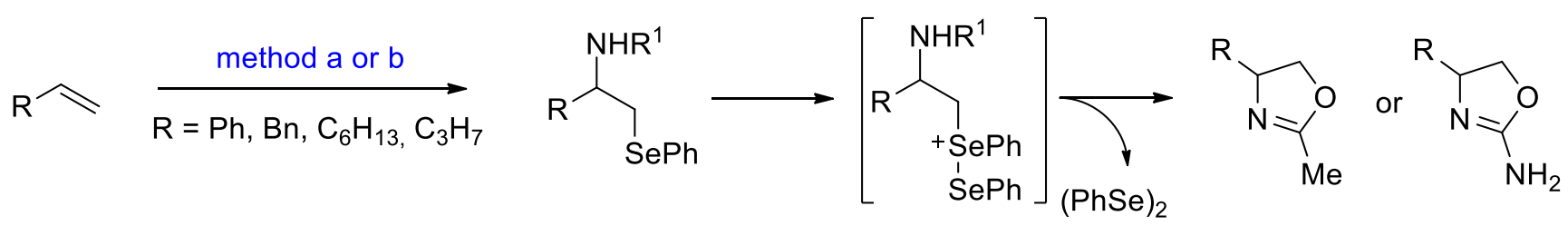

a. $(\mathrm{PhSe})_{2},\left(\mathrm{NH}_{4}\right)_{2} \mathrm{~S}_{2} \mathrm{O}_{8}, \mathrm{CH}_{3} \mathrm{CN}, \mathrm{TfOH}, \mathrm{H}_{2} \mathrm{O}, 60^{\circ} \mathrm{C}, 60 \%$ yield for $\mathrm{R}^{1}=\mathrm{COMe}$

b. $(\mathrm{PhSe})_{2},\left(\mathrm{NH}_{4}\right)_{2} \mathrm{~S}_{2} \mathrm{O}_{8}, \mathrm{NH}_{2} \mathrm{CN}, \mathrm{TfOH}, 1,4$-dioxane, $\mathrm{H}_{2} \mathrm{O}, 80^{\circ} \mathrm{C}, 54 \%$ yield for $\mathrm{R}^{1}=\mathrm{CN}$

Scheme 3. Cascade synthesis of oxazolines.

Hassner developed the first azidoselenylation of alkenes ${ }^{21}$ by addition of $\mathrm{PhSeCl}$ and sodium azide to simple alkenes in DMSO at room temperature. The reactions proceed with good anti stereospecificity, but poor regioselectivity, favouring Markovnikov addition products, as reported in Scheme 4 (examples a-b).

a.<smiles>C1=CCCCC1</smiles>

b.<smiles>C/C=C\c1ccccc1</smiles>

c.<smiles>CC1=CCC(C(C)C)CC1</smiles>

d.<smiles>CC(O)C=Cc1ccccc1</smiles><smiles>O=S(=O)(O[Na])O[Na]</smiles>
$91 \%$

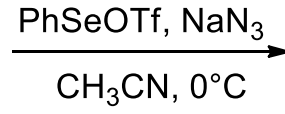
$65 \%$

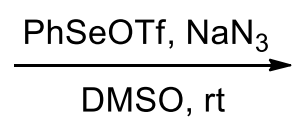
$73 \%$

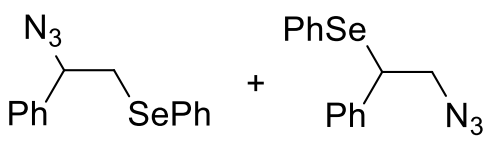

$63: 37$<smiles>CC(C)[C@H]1CC[C@@](C)(N)[C@H]([SeH])C1</smiles>

$87: 13$

Scheme 4. Azidoselenylations of alkenes.

In the same scheme more recent examples of seleno-azidations of terpenes ${ }^{22}$ and allylic alcohols ${ }^{23}$ are also reported (Scheme 4, examples c-d). These reactions were performed with phenylselenyl triflate generated by anion exchange from the corresponding bromide in the presence of silver triflate (AgOTf). The chiral arylselenyl triflates reported in Scheme 5 have been successfully employed to control the facial selectivity of the azidoselenylation. ${ }^{24-25}$ The intramolecular nonbonding interaction between the electrophilic selenium and the coordinating sulfur can force the chiral centre nearby the reactive centre and control the selectivity of the process with diastereoselectivity up to $97: 3 .^{25}$ 


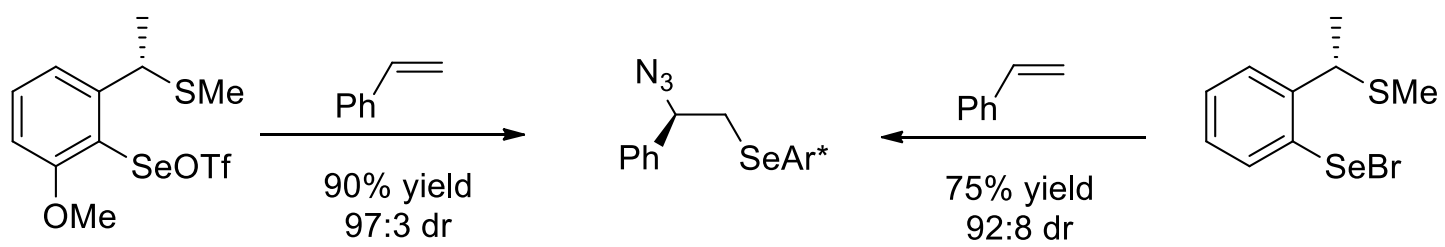

Scheme 5. Asymmetric azidoselenylations of alkenes.

Interestingly, anti-Markovnikov products were prepared with moderate diastereoselectivity through a radical-initiated azidation of alkenes with diphenyldiselenide, $\mathrm{NaN}_{3}$ and (diacetoxyiodo)benzene (PIDA) in dichloromethane at room temperature (Scheme 6, method a). ${ }^{26,27}$ Similar processes have been successfully applied to the functionalization of glycals (Scheme 6 , method b). ${ }^{28}$ In the reported examples, diversely protected D-galactal derivatives were transformed into the corresponding $\alpha$-selenoglicosides with complete regio- and stereo-selectivity.
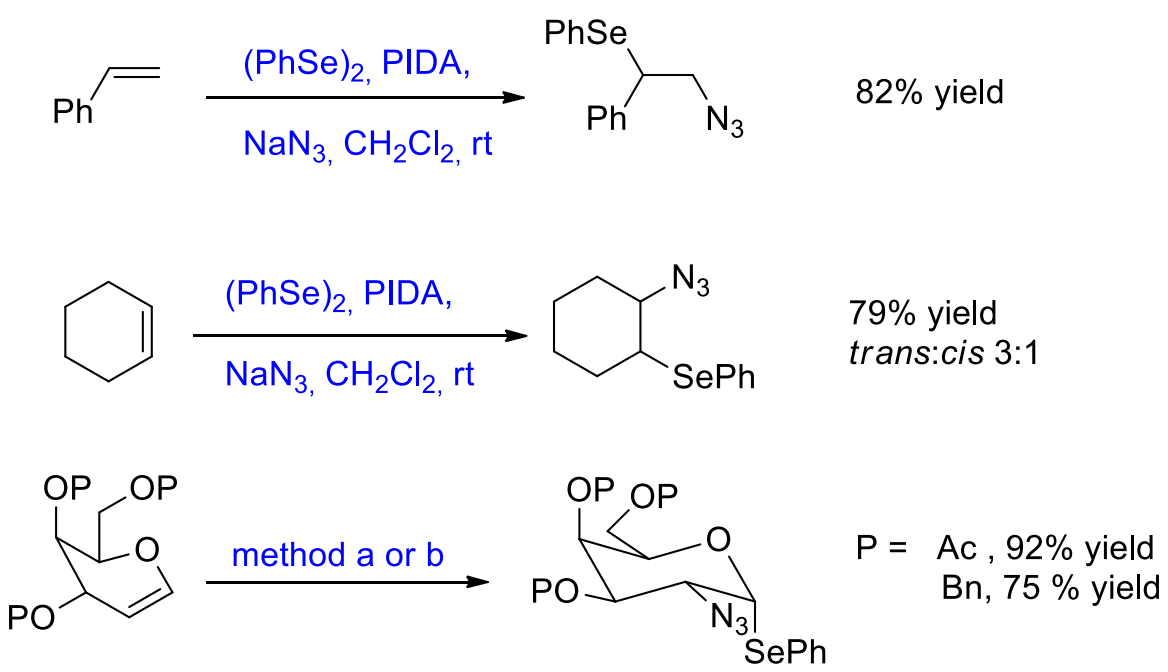

a. $\mathrm{P}=\mathrm{Ac},(\mathrm{PhSe})_{2}, \mathrm{PIDA}, \mathrm{NaN}_{3}, \mathrm{CH}_{2} \mathrm{Cl}_{2}, \mathrm{rt}$

b. $P=B n, N P S P, T M S N_{3}, T B A F, \mathrm{CH}_{2} \mathrm{Cl}_{2}$, rt

Scheme 6. Radical-initiated azidoselenylations of alkenes.

After the seminal works, new protocols have extended the scope of the selenoaminations to alternative nitrogen sources or optimized the generation of the electrophilic species according to the principles of sustainable chemistry. In 2015, Tang described a new amidoselenylation of styrene derivatives using NPSP as both the selenium and nitrogen source in the presence of $\mathrm{TiCl}_{4}$ (Scheme 7). ${ }^{29}$ In the proposed mechanism the reactions proceed through the formation of a seleniranium ion that can be trapped by the phthalimide nitrogen. Terminal and internal $E$ or $Z$ alkenes gave products in good yields, high Markovnikov-type regioselectivity and anti-stereospecificity. $N$-(phenylseleno)succinimide (NPSS) did not work in similar transformations. 

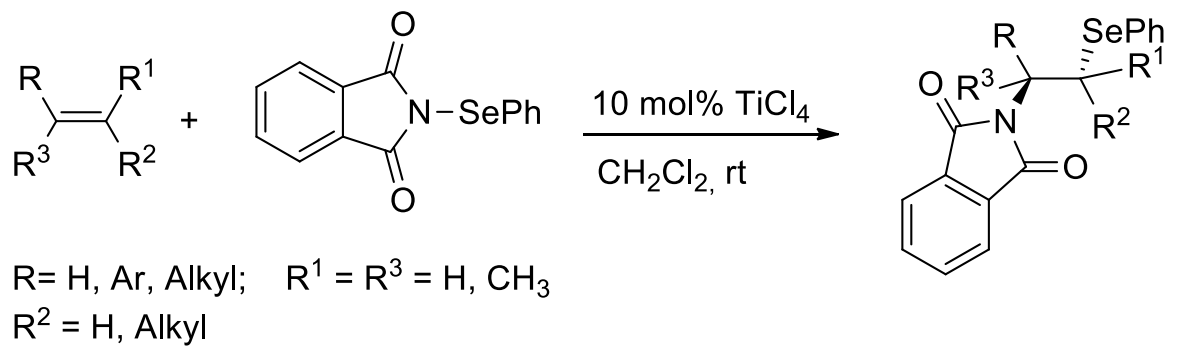

18 examples up to $93 \%$ yield

Scheme 7. $\mathrm{TiCl}_{4}$-imidation of alkenes with $\mathrm{N}$-phenylselenophthalimmide.

The production of electrophilic selenium species by oxidation of easy to handle and bench-stable diselenides under green conditions has been intensively investigated. Several protocols for the amido- or amino-selenylation of alkenes that avoid the use of strong acids or transition-metal salts have appeared in the recent literature. An example is the addition of saccharin to styrene or variously mono- or di-substituted alkenes successfully investigated in 2016 (Scheme 8). ${ }^{30}$ The reaction was carried out with diphenyl diselenide and potassium persulfate as the oxidant to generate a selenylating agent with a non-nucleophilic counterion. The transition metal-free method was also applied to the addition of other pharmaceutically relevant amino sources such as sulfonimides, di-, tri- or tetra-azoles, and purines.

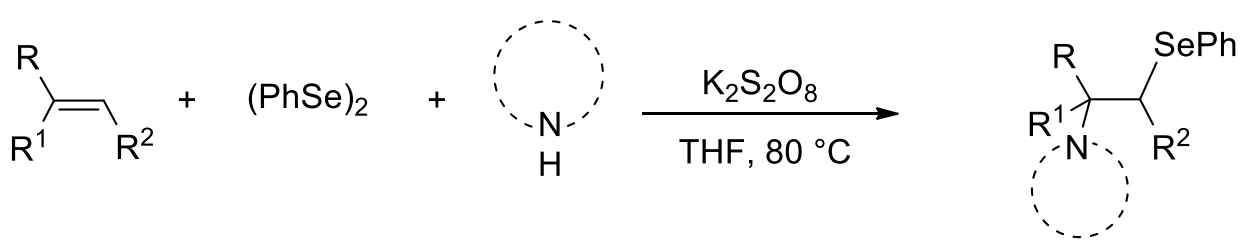

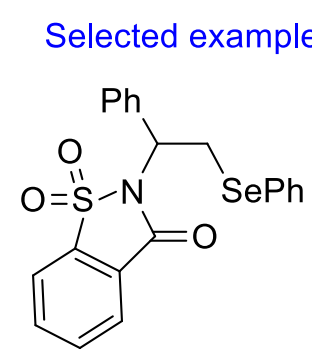

$12 \mathrm{~h}, 89 \%$

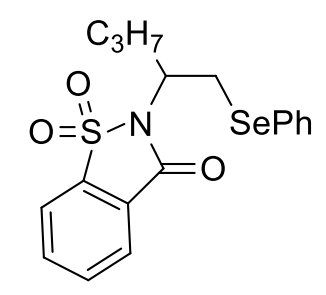

$4 \mathrm{~h}, 79 \%$

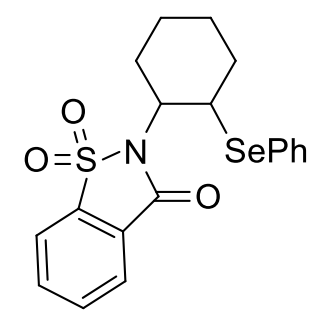

$4 \mathrm{~h}, 86 \%$

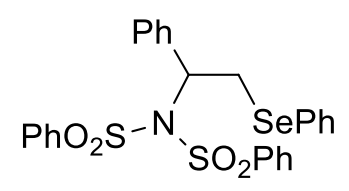

$12 \mathrm{~h}, 84 \%$<smiles>c1ccc(CC(c2ccccc2)n2cncn2)cc1</smiles>

$12 \mathrm{~h}, 81 \%$

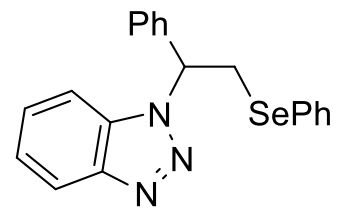

$12 \mathrm{~h}, 95 \%$

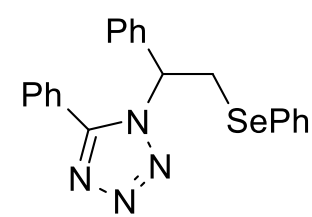

$12 \mathrm{~h}, 76 \%$

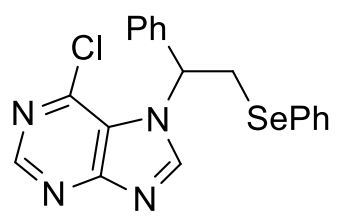

$12 \mathrm{~h}, 66 \%$

Scheme 8. Aminoselenylation reactions of alkenes with sulfonimides, azoles or purines.

The addition of benzotriazoles to alkenes was also promoted by molecular iodine (Scheme 9). ${ }^{31}$ As reported in the scheme, the iodine reacts with equimolecular amounts of diselenide inducing a fast Se-Se bond cleavage and the in situ formation of the electrophilic species. Good yields were obtained with styrene 
derivatives. Conversely, modest results were collected when reactions were performed with alkyl monosubstituted alkenes or cyclic alkenes.

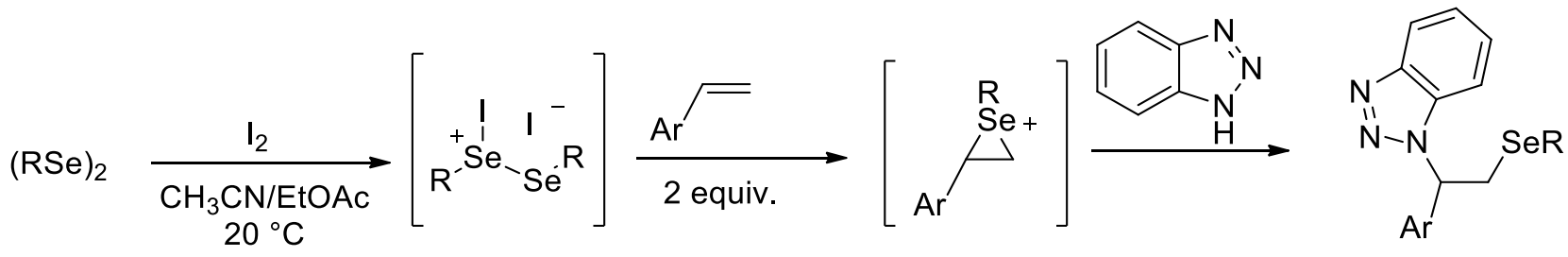

Scheme 9. lodine-mediated aminoselenylation of alkenes with benzotriazoles.

A similar protocol involving a diselenide, molecular iodine and an alkene provided the access to 1,2selenosulfonamides with high regioselectivity and broad structural and functional group tolerance (Scheme 10). ${ }^{32}$ Contrary to what observed in the previous case, authors suggest the involvement of radical selenium species in the reaction mechanism.

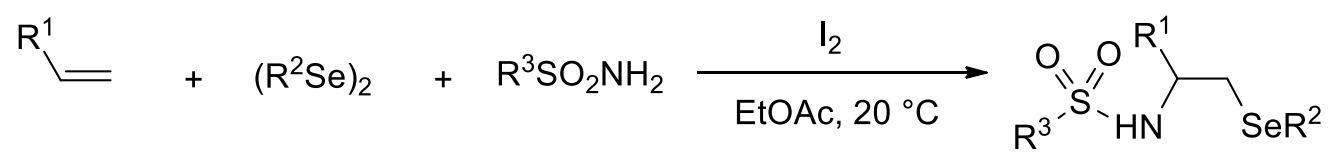

Selected examples:

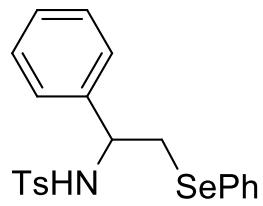

$87 \%$

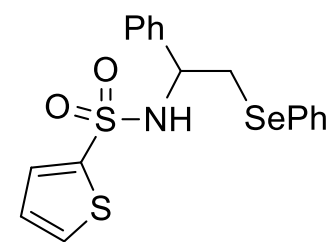

$85 \%$

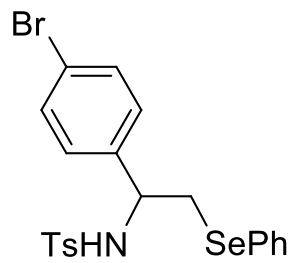

$83 \%$

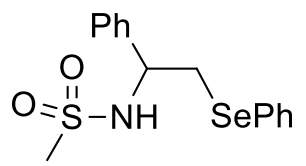

$92 \%$

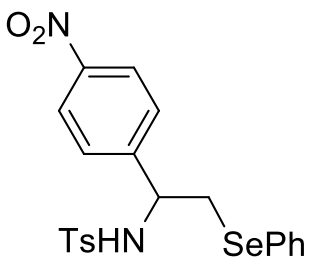

$71 \%$<smiles>[AlH2]NC(C[Se]c1cccs1)c1ccccc1</smiles>

$82 \%$

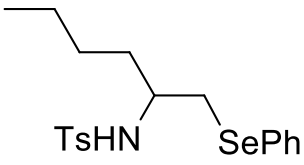

$80 \%$

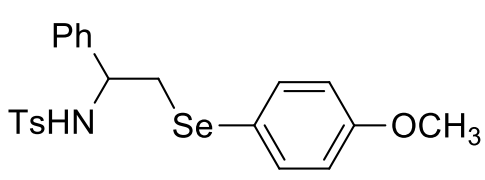

$87 \%$

Scheme 10. lodine-mediated sulfonamidoselenylation of alkenes.

The production of electrophilic selenium species from different diaryl diselenides by using oxygen as terminal oxidant has been also developed (Scheme 11). ${ }^{33}$ Several examples are disposable with a broad nitrogen source scope including benzotriazoles, di- and triazoles, purines, and sulfonimides. Notably, the reaction gave good results also on a gram-scale. Mechanistic insights seem to confirm a ionic pathway with the formation of classical seleniranium intermediates. 

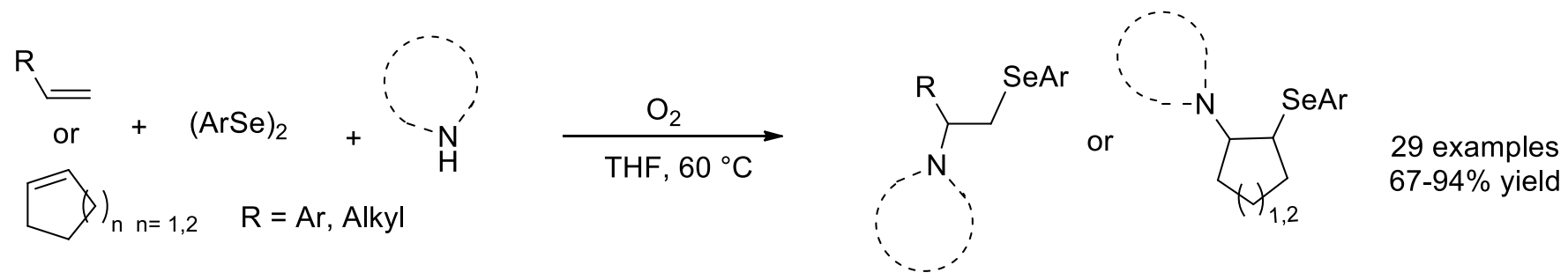

Scheme 11. $\mathrm{O}_{2}$-mediated oxidation of diselenides for aminoselenylation reactions.

In Scheme 12, an electrochemical aminoselenylation of styrene derivatives is described. This method gave products with wide nitrogen scope, high regioselectivity and reasonable to good yields under additive-free conditions at room temperature. ${ }^{34}$ It also extended the scope of the intermolecular aminoselenylation of alkenes to anilines, not employed before.

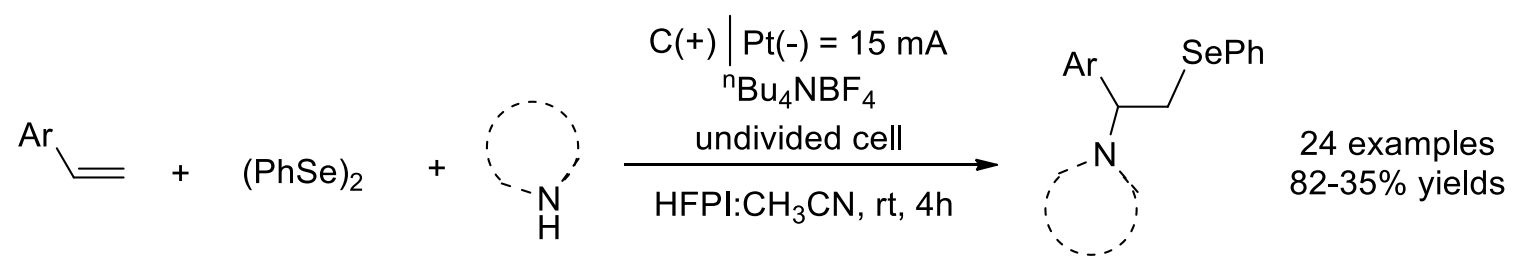

$\mathrm{N}$ source $=$ benzotriazoles, pyrazoles, sulfonamides and anilines $\mathrm{HFPI}=1,1,1,3,3,3$-hexafluoro-2-propanol

Scheme 12. Electrochemical aminoselenylations.

Very recently, nitrogen containing functional groups have been also incorporated onto C-C triple bonds for a convenient and stereo-controlled access to synthetically valuable vinyl selenides. ${ }^{35-38}$ In 2016 the first highly regio- and stereo-selective functionalization of alkynes with diphenyldiselenide and $\mathrm{N}$ fluorobenzenesulfonimide (NFSI) has appeared in the literature (Scheme 13). ${ }^{39}$

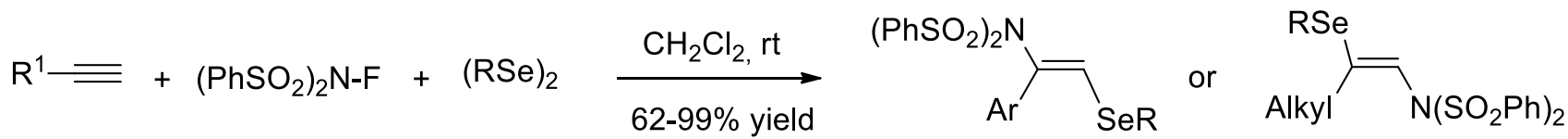

$$
\begin{aligned}
& \mathrm{R}^{1}=\text { Aryl or Alkyl; } \mathrm{R}=\mathrm{Ph}, \mathrm{Bn} \quad \text { Markovnikov anti-Markovnikov }
\end{aligned}
$$

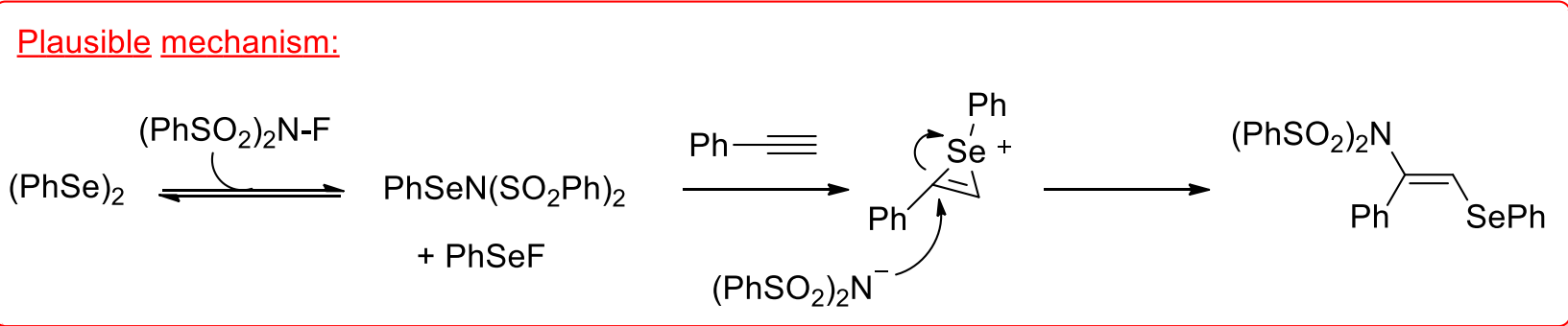

Scheme 13. Imidoselenylations of alkynes.

NFSI is a strong oxidant. It can generate the two electrophilic selenium species reported in Scheme 13, and also acts as nitrogen source. Reactions were carried out on both aryl and aliphatic terminal alkynes and gave 
enamides with opposite regiochemistry and anti selectivity. Authors suggested that the formation of the products is electronically controlled with nucleophilic attack at the benzylic carbon (Markovnikov regioselectivity) in the case of aryl-substituted alkynes, or sterically controlled (anti-Markovnikov regioselectivity) in the case of alkyl-substituted alkynes. Also internal alkynes were successfully functionalized. Interestingly the related thiamination of alkynes occurred only under Lewis acid catalysis, probably as a consequence of the lower stability of the sulfur electrophilic species with respect to the selenylated one.

The same combination of NFSI and diselenides was used for the decarboxylative functionalization of alkynes (Scheme 14). ${ }^{40}$ In these reactions polyseleno substituted enamides were formedin good to excellent yields by effect of sequential addition of the selenium electrophile to C-C unsaturated bond followed by elimination of $\mathrm{CO}_{2}$. The reaction is general and both aryl propiolic acids and alkynyl carboxylic acids are competent substrates. The unsubstituted propiolic acid gave the triseleno derivatives in $81 \%$ yield. In the case of aryl-substituted propiolic acids better results were obtained in the presence of electron-donating groups on the aromatic ring. Unfortunately cinnamic acids were unreactive. The scope of the diselenides was also wide, including not only variously substituted aryl diselenides, but also diheteroaryl and dialkyl diselenides.

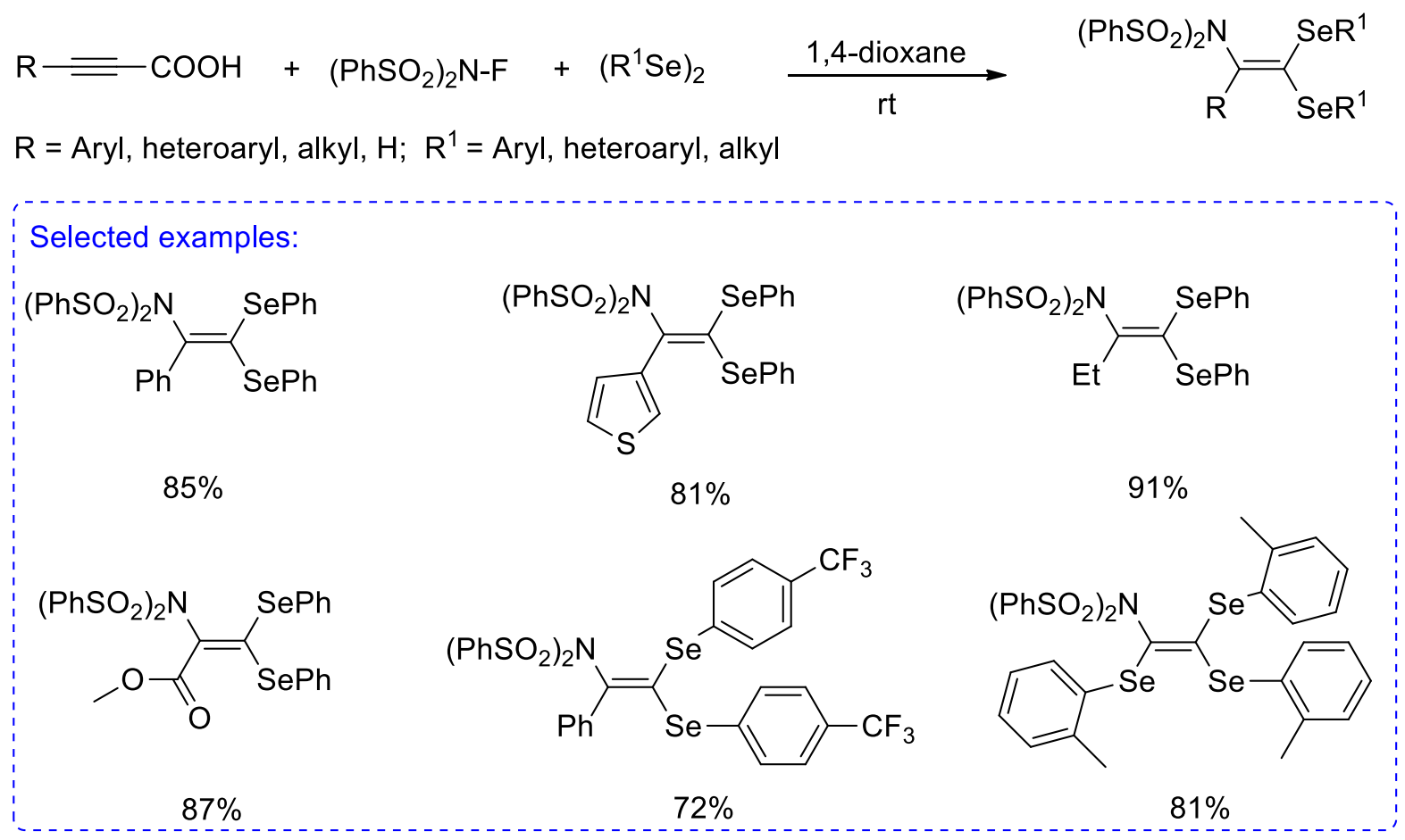

Scheme 14. Decarboxylative imidoselenylations of alkynes.

\section{Intramolecular Aminoselenylations of C-C Double or Triple Bonds}

Electrophilic selenocyclizations (cyclofunctionalizations) of alkenes containing internal nitrogen nucleophiles are very well documented ${ }^{1-6}$ and some of these reactions have found interesting applications in the preparation of complex molecules and alkaloids. Representative examples are reported in Scheme 15. 

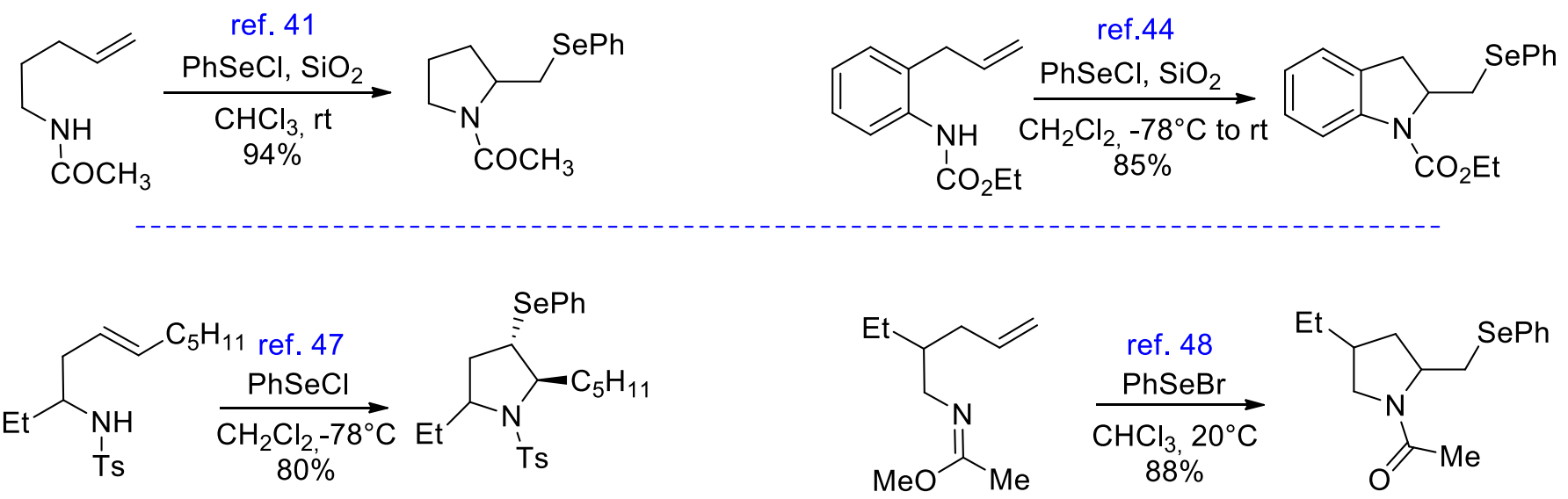

ref. 52
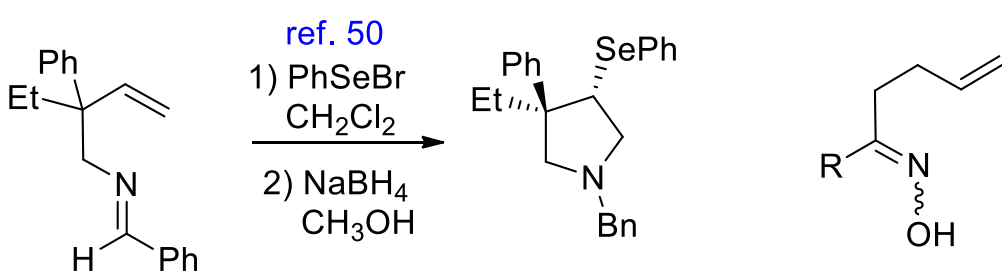

$(\mathrm{PhSe})_{2}$

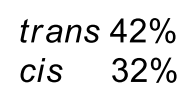

$$
\begin{array}{ll}
\mathrm{R}=\mathrm{Me} & Z: E=1: 2 \\
\mathrm{R}=\mathrm{Ph} & \text { only } E
\end{array}
$$

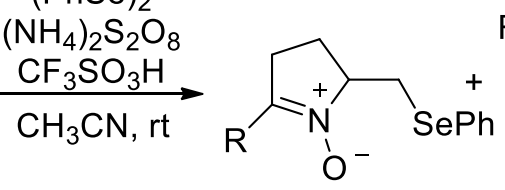

$$
58 \%
$$$$
0 \%
$$

$20 \%$

$78 \%$

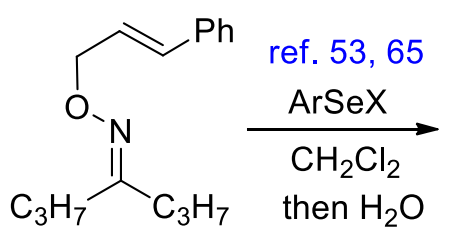

with $\mathrm{PhSeBr}$

with

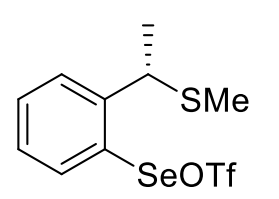

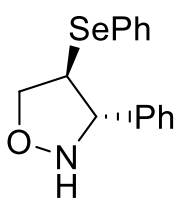

$87 \%$

$77 \%$ dr $93: 7$<smiles>[R]C([R])(C/C=C/C)/C(=N/Nc1ccccc1)c1ccccc1</smiles>

ref. 54

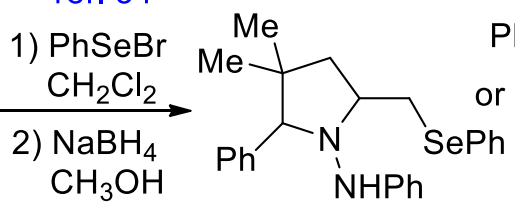<smiles>PN1N=C(c2ccccc2)CCC1C[SbH2]c1ccccc1</smiles>

$68 \%$

$$
\mathrm{R}=\mathrm{Me} \quad Z
$$<smiles>[R]C1=NOC(C[SeH]c2ccccc2)CC1</smiles>

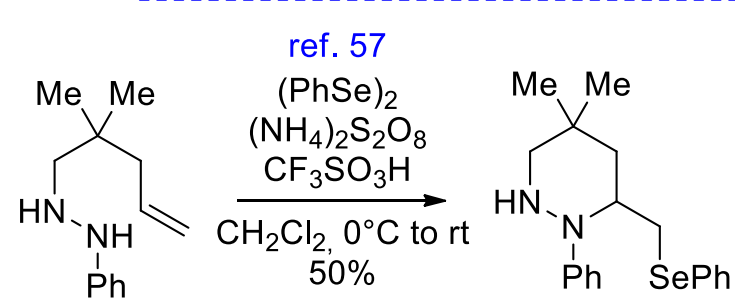

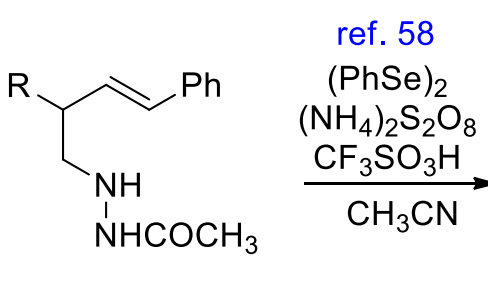

$\mathrm{R}=\mathrm{Ph}$

$\mathrm{R}=\mathrm{Me}$<smiles>[R]C1NN(C(C)=O)[C@H]([Sb]c2ccccc2)[C@H]1c1ccccc1</smiles>

$71 \%$ $82 \%$

Scheme 15. Synthesis of nitrogen-containing heterocycles by intramolecular aminoselenylations of alkenes.

Common substrates are alkenes bearing electron-deficient nitrogen containing functional groups such as amides, carbamates, and sulfonamides. ${ }^{41-47}$ The nucleophilicity of $s p^{2}$ hybridized nitrogen atoms is sufficient to 
intramolecularly trap the seleniranium intermediates. In fact, several ring forming reactions were performed with unsaturated imidates, imines and its derivatives such as oximes and hydrazones. ${ }^{48-54}$ In these processes, the ring-closure reaction can be followed by fragmentation, ${ }^{48}$ reduction with borohydrides or hydrolysis of the initially formed iminium compounds. Primary alkenamines seem not competent substrates for selenocyclizations, ${ }^{45}$ however, successful reactions were performed with unsaturated hydroxylamines or hydrazines. ${ }^{55-58}$ In general, exo or endo cyclization modes can occur, depending on the chain length, substitution pattern, nature of the nitrogen protecting group and geometrical alignment of the substrate as well as the ring size of the formed product. A number of 5- or 6-membered heterocycles have been formed, not only through 6-exo-trig, 6-endo-trig, or 5-exo-trig cyclizations, but also through less common 5-endo-trig ${ }^{59}$ ring closures. Related asymmetric cyclizations have been developed starting from chiral diselenides. ${ }^{60-65}$

Interestingly, in the presence of bidentate nucleophilic groups, competitions in the ring closure by the different atoms can lead to different heterocycles. An example is the cyclization of alkenamides in which both the oxygen and the nitrogen atom could give rise to rings of the same size. In these cases the cyclization afforded cyclic imidates and not lactams as a consequence of the exclusive formation of the C-O bond. A recent example is reported in Scheme $16 .{ }^{66}$ Isobenzofurans were obtained in acceptable to good yields, regardless of the nature of the substituent at the nitrogen atom. Remarkably, some selenium-promoted cyclizations with hydroxamic acids have been driven towards the exclusive formation of lactams as a function of the experimental conditions employed. ${ }^{67-68}$
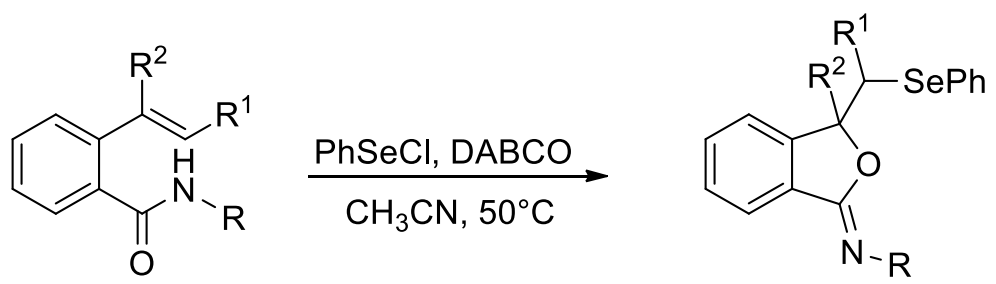

21 examples $37-91 \%$ yield

Scheme 16. Imidates from selenocyclizations of amides.

In the recent years new synthetic protocols have been studied for the assembly of challenging and/or pharmaceutically attractive heterocyclic scaffolds by intramolecular aminoselenylation. An example is the formation of the azetidines reported in Scheme 17. ${ }^{69-70}$ Homo-allylic secondary amines, when treated with phenyselenyl halides, can generate azetidines or pyrrolidines as the result of an 4-exo-trig or 5-endo-trig cyclization, respectively. It was recently demonstrated that the regioselectivity of the process is strictly related to the substitution pattern. The introduction of one or more substituents (Thorpe-Ingold effect) in the openchain reactant had beneficial effects on the yield of cyclization. Moreover the nature and the position of the substituents deeply affected the outcome of the reaction. In fact, $\gamma$-substituted homoallylic amines gave azetidines in reasonable to good yields, complete regioselectivity and good diastereoselectivity, favouring the 2,4-cis diastereoisomer. With a phenyl group located in the $\delta$-position, the regioselectivity of the reaction was completely reversed furnishing mainly 2,5-cis-pyrrolidines. Similar reactions were used to generate halopyrrolidines. $^{71}$ 


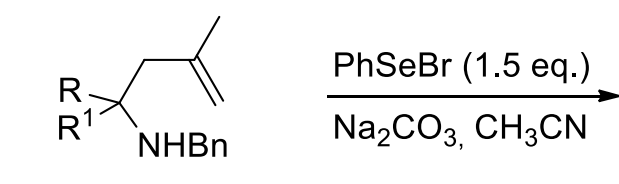

$\mathrm{R}=\mathrm{H}$ or $\mathrm{Me} ; \mathrm{R}^{1}=\mathrm{Me}, \mathrm{Et}, i \mathrm{Pr}, t \mathrm{Bu}, \mathrm{Ph}$

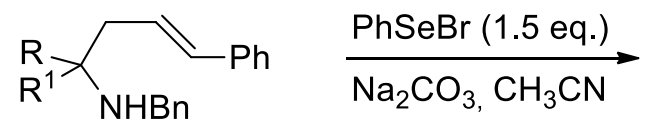

$\mathrm{R}=\mathrm{H}$ or $\mathrm{Me} ; \mathrm{R}^{1}=\mathrm{Me}, \mathrm{Et}, \mathrm{Pr}, \mathrm{Ph}$

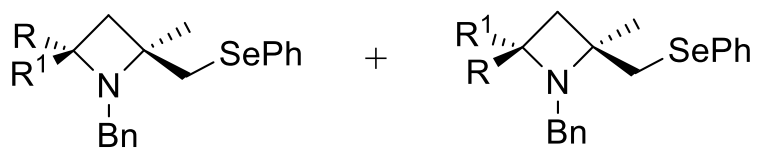

$35-72 \%$ yield $\quad$ for $\mathrm{R}=\mathrm{H}$ cis:trans $>8: 2$

$55-88 \%$ yield for $\mathrm{R}=\mathrm{H}$ cis:trans $>8: 2$

Scheme 17. Regioselective synthesis of azetidines and pyrrolidines.

Enantiopure pyrrolidines ${ }^{72}$ and pyrrolizines ${ }^{73}$ were synthesized from commercially available aminoalcohols usingthe 5-exo-trig ring closure reaction promoted by $\mathrm{N}$-(phenylseleno) phthalimide in the presence of a catalytic amount of $\mathrm{BF}_{3} \cdot \mathrm{Et}_{2} \mathrm{O}$ as the key step. Tin-mediated radical allylations of selenides were employed for the insertion of the allylic groups on the chiral source, taking advantage of the relatively easy homolytic cleavage of the SePh group. An example of the synthetic sequence is shown in Scheme 18.
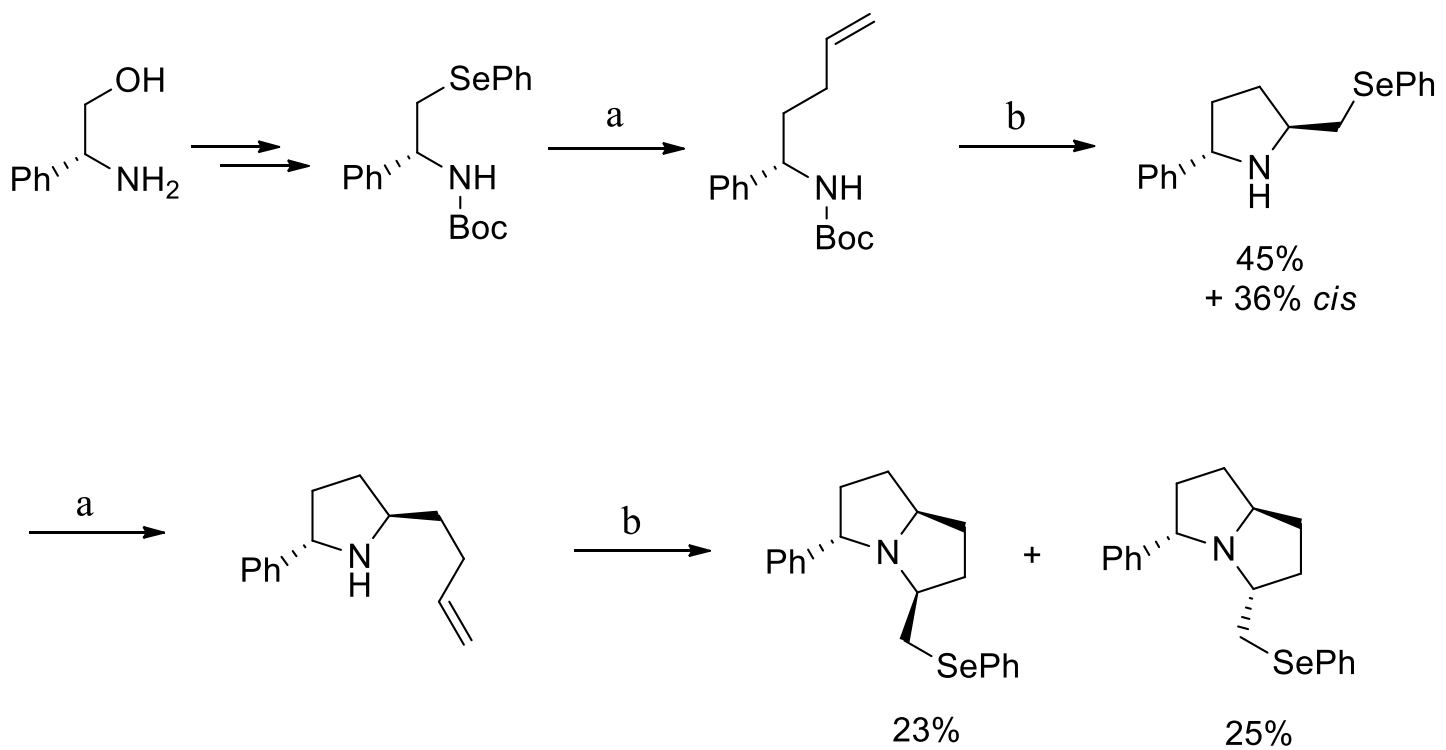

a. $\mathrm{SnBu}_{3}, \mathrm{AIBN}, \mathrm{C}_{6} \mathrm{H}_{6}, 80^{\circ} \mathrm{C} ; \quad$ b. NPSP, $\mathrm{BF}_{3} \cdot \mathrm{Et}_{3} \mathrm{O}, \mathrm{CH}_{2} \mathrm{Cl}_{2}, \mathrm{rt}$

Scheme 18. Synthesis of enantiopure pyrrolidines and pyrrolizines.

Recently, selenocyclizations provided access to the bicyclic hydantoins reported in Scheme $19 .^{74}$ Hydantoins are useful intermediates in the synthesis of $\alpha$-aminoacids and exhibit several biological activities. For these reasons these compounds are considered attractive targets in drug discovery programs. Reactions were regioselective and generated Markovnikov-type hydantoin derivatives in poor to good yields through a 5-exo-trig cyclization. The diastereoselectivity was moderate and compounds with bridgehead substituents 
and phenylseleno groups in cis configuration were achieved, mainly. The method tolerated several substitutions at the double bond, and gave access to products with good structural diversity. The mechanism and selectivity of the reaction were investigated by density functional theory (DFT) methods. ${ }^{75}$<smiles>[R]C([R])=C([R])CC([R])C1([R])NC(=O)NC1=O</smiles>

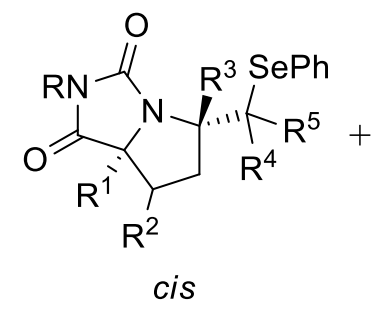<smiles>[R]C1CC(C([R])([R])[Se]c2ccccc2)N2C(=O)NC(=O)C12[R]</smiles>

Scheme 19. Synthesis of bicyclic hydantoins.

As mentioned before, the selenium-mediated aminocyclization of C-C double bonds found useful application in the total synthesis of natural products (Scheme 20).
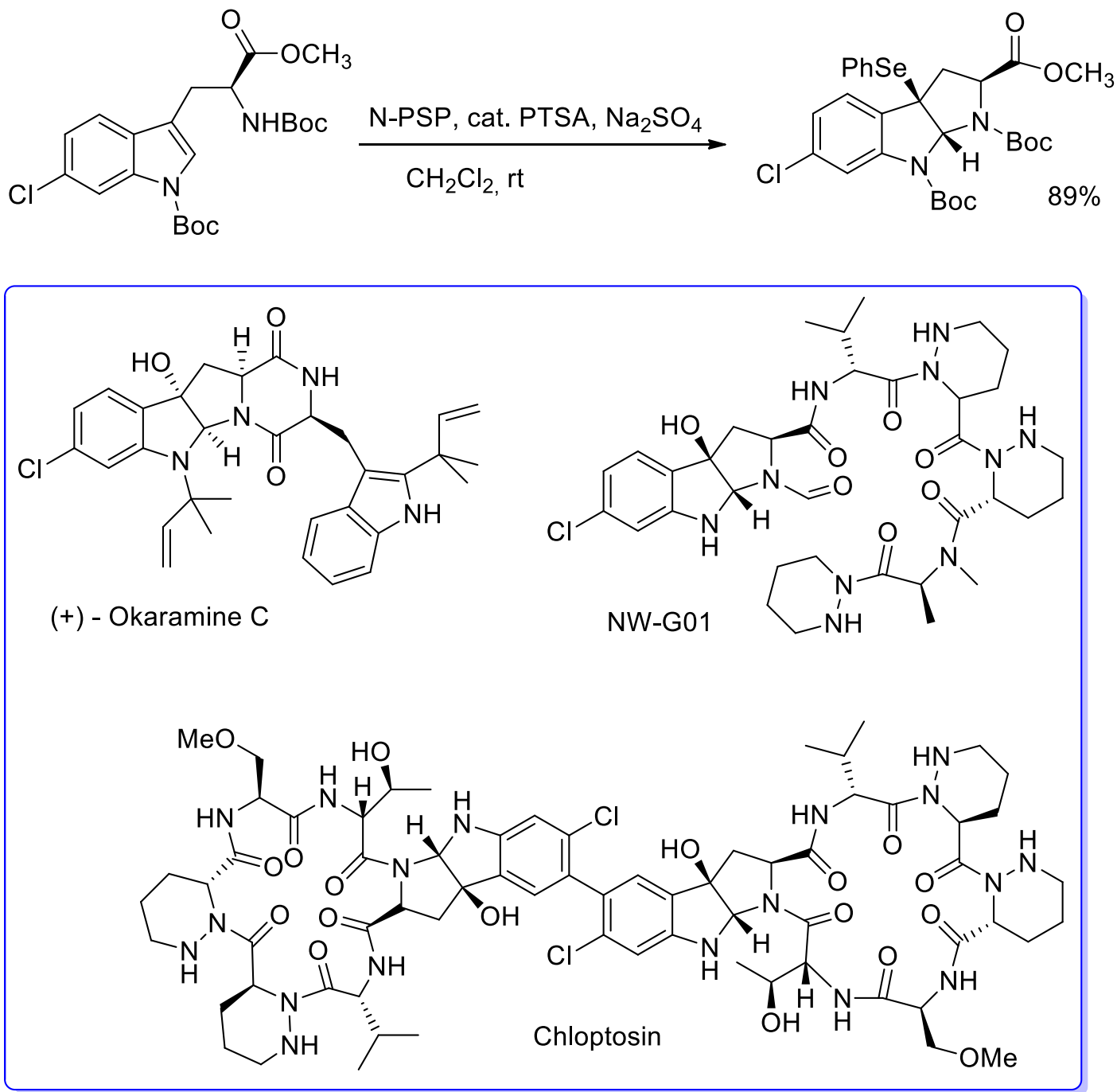

Scheme 20. Synthesis of the pyrroloindole fragment of some alkaloids. 
Since the pioneering works by Danishefsky ${ }^{76-77}$ and $\mathrm{Crich}^{78}$ the NPSP-mediated cyclization of L-tryptophan derivatives has been mechanistically investigated and employed for the rapid and stereoselective assembly of the synthetically challenging hexahydropyrrolo[2,3-b]indole core of Okaramine C and other alkaloids. ${ }^{79-81}$

The selenocyclization reaction afforded the indicated kinetically favoured exo isomer with high diastereo control. Recently, Leyet al. ${ }^{82}$ employed such reaction in the total synthesis of Chloptosin, a structurally challenging anticancer agent isolated from culture broth of Streptomyces, and Hatakeyamaet al..$^{83}$ in the synthesis of the cyclic hexapeptide antibiotic NW-G01 from fermentation broth of Streptomyces alboflavus. In both cases, the hydroxylated heterocyclic core, typical of the aforementioned alkaloids, was obtained under mild conditions by oxidative deselenylation with wet $m$-CPBA in the presence of $\mathrm{K}_{2} \mathrm{CO}_{3}$.

In 2013 an organocatalyzed asymmetric variant of this cyclization has been developed. Tryptamine derivatives reacted with NPSP in the presence of a BINOL-based phosphoric acid affording pyrrolo[2,3b]indoles with good yields and enantiomeric excess values in the range $71-89 \% .{ }^{84}$ Different substitution patterns were tolerated, regardless the electronic nature and the position of the substituent on the indoline ring. The protocol was applied to the synthesis of the key chiral precursor of the (+)-alline (Scheme 21).
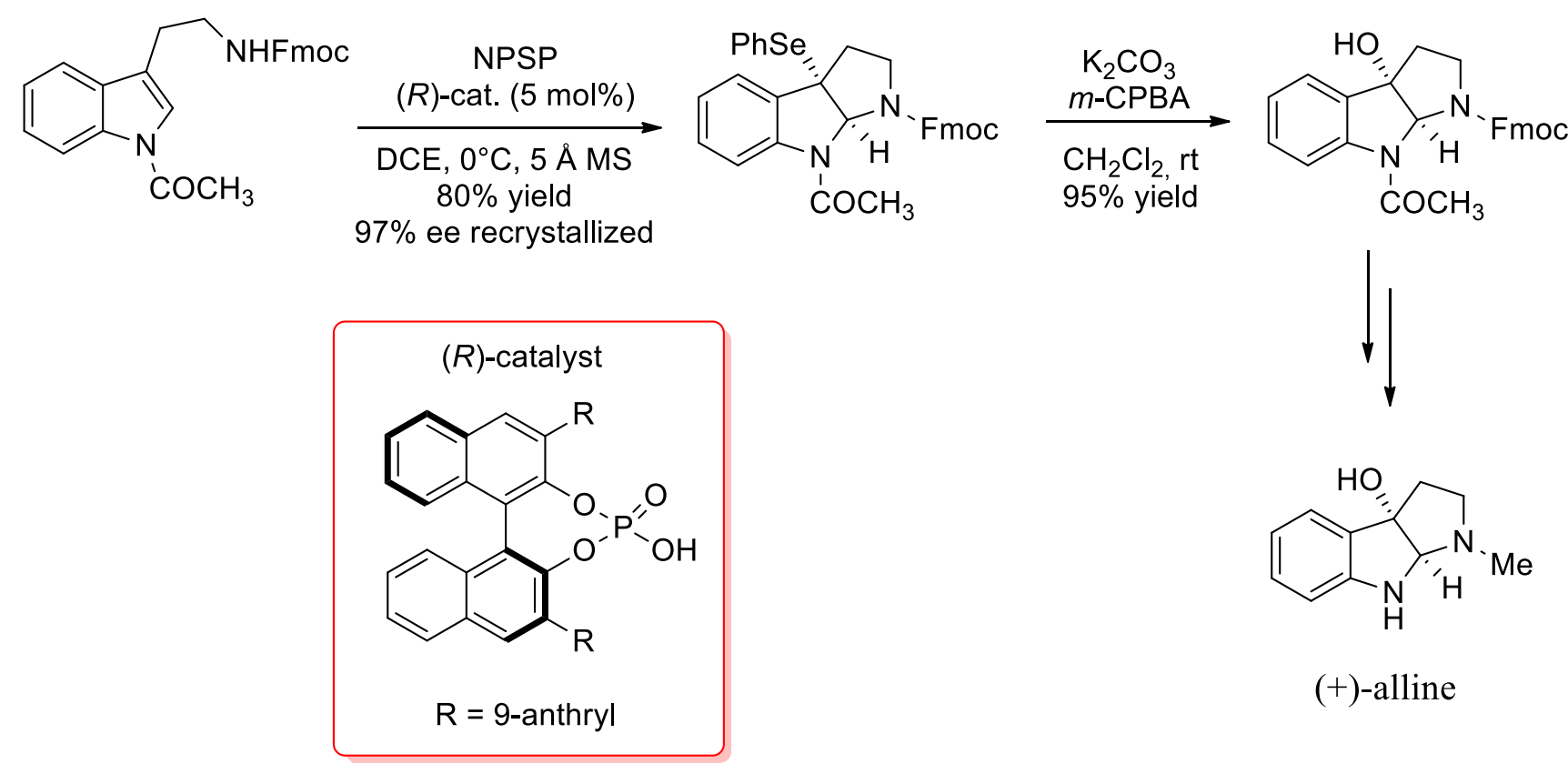

Scheme 21. Asymmetric organocatalyzed intramolecular aminoaselenylation.

Also in selenocyclizations novel methods for the generation of the electrophilic selenium species have been attempted. A visible-light promoted selenocyclization of alkenes has been recently developed (Scheme 22).$^{85} \mathrm{PhSeBr}$ was generated in situ from equimolar amounts of diphenyldiselenide and tetrabromomethane with Blue LED irradiation without the need of inert atmosphere. The reaction occurred at room temperature, not only in dichloromethane, but also in nucleophilic solvents such as methanol, with excellent results in terms of yields and reaction times. The method gave an efficient access to pyrrolidines and piperidines and it was applied to the short synthesis of the racemic $y$-lycorane, an alkaloid isolated from Amaryllidaceae. Interestingly, the selenocyclization is followed by a radical ring closure through homolytic cleavage of the selenium moiety with tris(trimethylsilyl)silane (TTMSS) and AIBN in benzene under reflux. The forth ring was obtained in an acceptable $44 \%$ yield, together with $41 \%$ yield of the by-product due to hydrogen abstraction. 
<smiles>C=CCCCNPP</smiles>

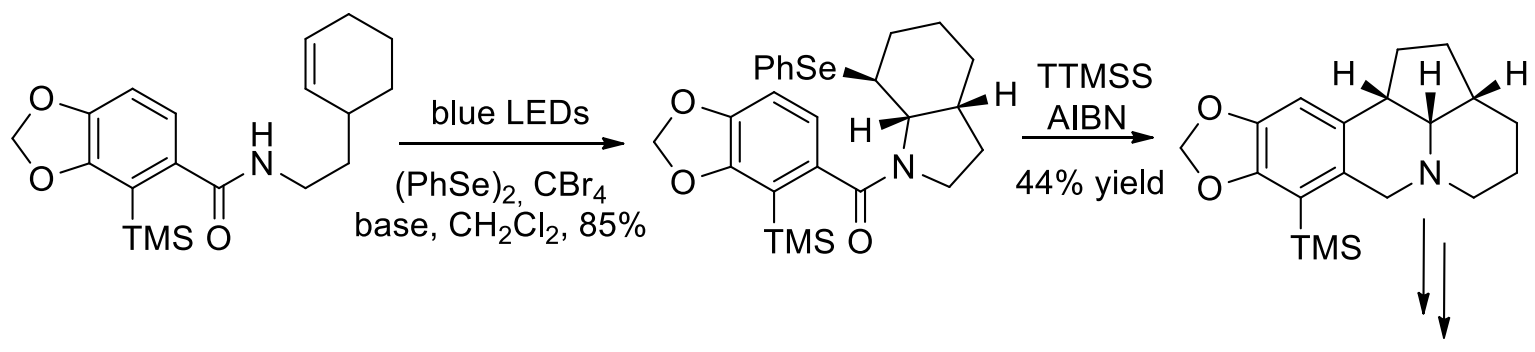

$( \pm)-\gamma$-lycorane

Scheme 22. Visible-light promoted intramolecular aminoselenylations and synthesis of $\mathrm{p}$-lycorane.

This year, the photocatalytic selenoaminocyclization of the $\mathrm{N}$-tosyl-4-pentenamine in the presence of a catalytic amount of 1,2,3,5-tetrakis(carbazol-9-yl)-4,6-dicyanobenzene (4CzIPN) has been successfully investigated (Scheme 23). ${ }^{86}$ This first sporadic example of photocatalytic aminocyclization is an interesting result towards the goal of sustainable intramolecular selenoaminations, since it uses ambient air for the generation of the electrophilic species and provides only water as the by-product.

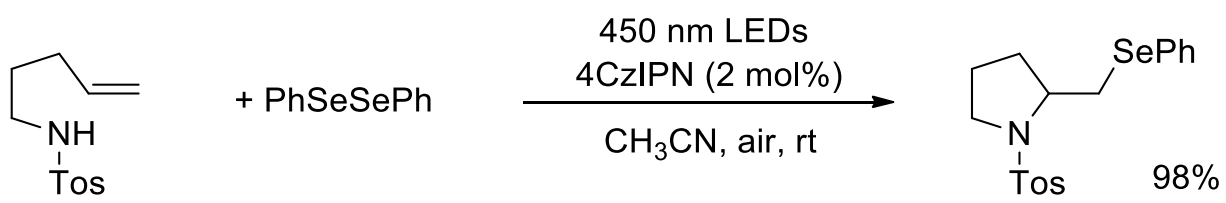

Scheme 23. Photocatalytic intramolecular aminoselenylation.

Selenocyclizations were not restricted to alkenes, since also alkynes proved to be competent substrates. These reactions have given access to pharmaceutically relevant seleno-substituted heteroaromatic compounds such as indoles and pyrazoles. Scheme 24 shows the $\mathrm{Cs}_{2} \mathrm{CO}_{3}$-assisted copper-catalyzed selenofunctionalization of 2-alkynylanilines for the formation of 3-fenylselenylindoles. ${ }^{87}$ Mechanistic studies suggested the cooperation of the diselenide and copper salt in the generation of the electrophilic species. 


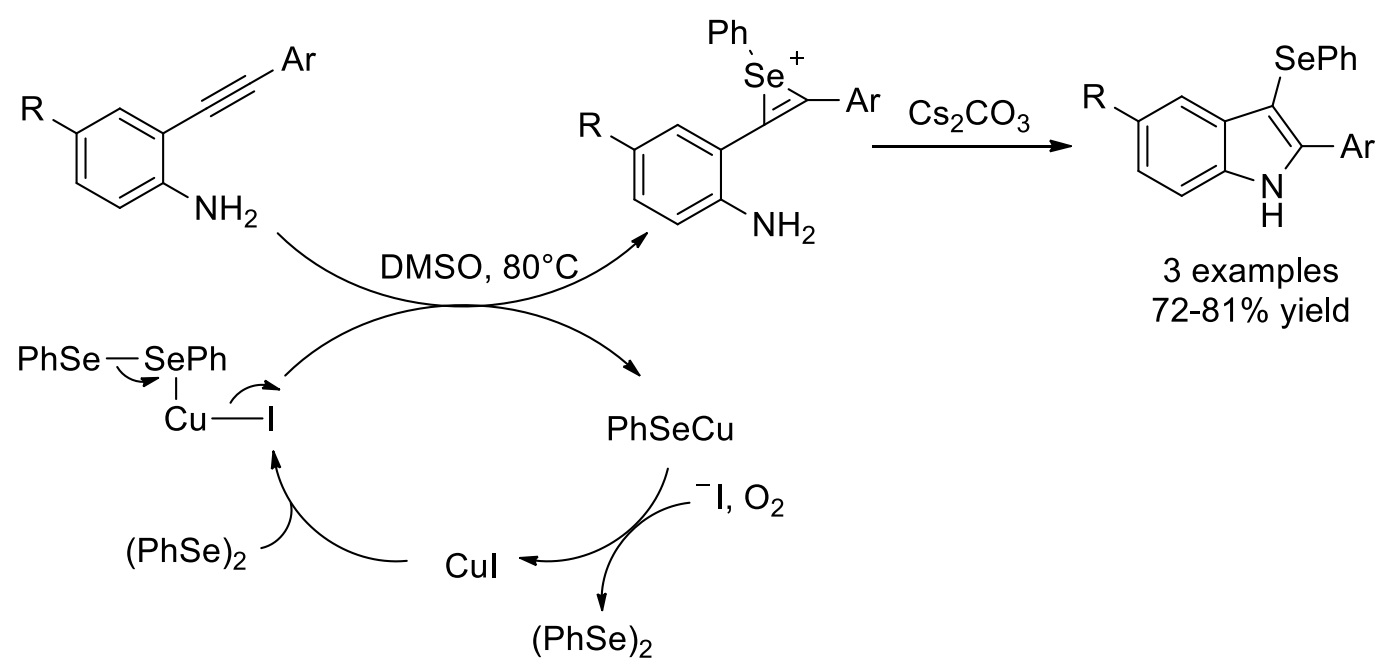

Scheme 24. Synthesis of 3-selenylindoles by intramolecular aminoselenylation of alkynes.

Similarly, the formation of 3-organoselenoquinolines have been observed upon treatment of (2aminoaryl)-2-ynols with diaryl or dibutyl diselenides and an excess of $\mathrm{FeCl}_{3}$ as the result of a regioselective 6endo-dig cyclization (Scheme 25 , route a) ${ }^{88}$ Interestingly, 2-alkynylbenzamides, failed to generate isoquinolin$1(2 \mathrm{H})$-ones. ${ }^{89}$ As expected for amides, the oxygen/nitrogen competition favoured the $\mathrm{C}-\mathrm{O}$ bond formation and the generation of 4 -arylselenyl- $1 \mathrm{H}$-isochromen-1-imines (Scheme 25 , route b).

a.<smiles>[Y]c1ccc(N)c(C([R])(O)C#C[Al])c1</smiles>

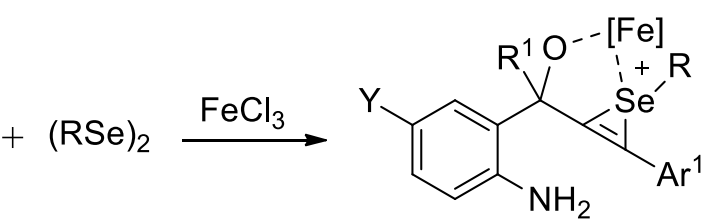<smiles>[3H]</smiles>

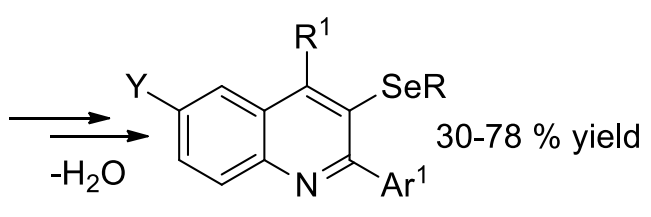

b.<smiles>[Z]c1ccc(C(N)=O)c(C#C[Al]Br)c1</smiles><smiles>[Z]c1ccc(C(N)=O)c(C2=C([Al])[Se]2=[Te])c1</smiles><smiles>[R]Sc1c([Al]C)oc(=[W])c2ccc([Z])cc12</smiles>

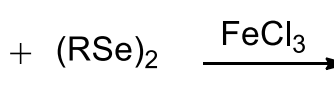

$\mathrm{Y}=\mathrm{H}, \mathrm{Cl}, \mathrm{NO}_{2} ; \mathrm{Z}=\mathrm{H}, \mathrm{OMe}, \mathrm{F} ; \mathrm{R}=\mathrm{Ar}$ or $\mathrm{Bu}$

Scheme 25. Synthesis of 4-arylselenyl-1H-isochromen-1-imines .

Scheme 26 shows a new metal- and halogen-free route for the synthesis of 4-arylselenyl-1H-pyrazoles ${ }^{90}$ employing alkynyl hydrazones, diorganyl diselenides and Oxone ${ }^{\circledast} .{ }^{77}$ Se NMR and High Resolution Mass studies suggested that the oxidation of the diselenides with $\mathrm{Oxone}^{\circledast}$ in $\mathrm{EtOH}$ at $70{ }^{\circ} \mathrm{C}$ produces several electrophilic selenium species such as $\mathrm{PhSeOSO}_{3}{ }_{3}$, benzenseleninic acid $\left(\mathrm{PhSeO}_{2} \mathrm{H}\right)$ and the corresponding ester $\left(\mathrm{PhSeO}_{2} \mathrm{Et}\right)$. Selenylated pyrazoles were recovered in high yields with broad substrate scope. 


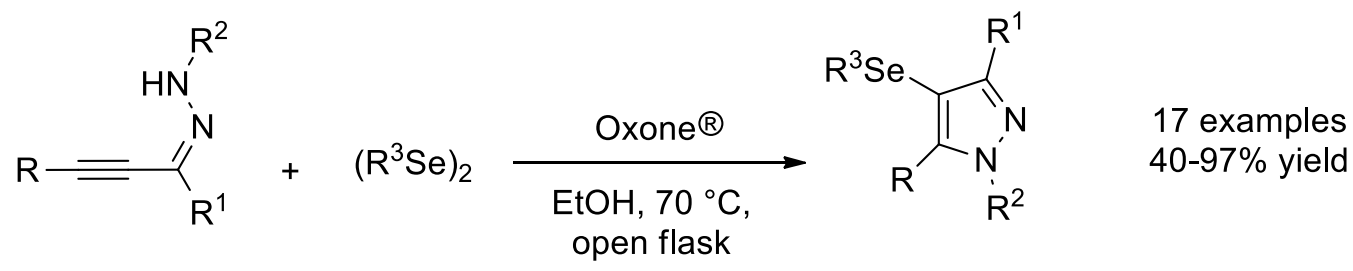

Scheme 26. Synthesis of 4-arylselenyl-1H-pyrazoles.

Finally, in 2012 Menichetti and co-workers disclosed the synthesis of benzo[b][1,4]selenazines by the reaction of $\mathrm{N}$-sulfonylamino diselenides with electron-rich alkenes, a catalytic amount of a copper(II) Lewis acid and triethylamine. ${ }^{91-92} E$ and $Z$ disubstituted electron-rich alkenes gave products with retention of configuration. Authors suggested a mechanism involving a [4+2]-cycloaddition between the electron-rich alkene and the intermediate 2-iminoselone, rather than a classical electrophilic selenocyclization, as reported in Scheme 27. Similar compounds were synthesized and evaluated as carbonic anhydrase inhibitors. ${ }^{93}$ These $^{2}$ metallo-enzymes play an important role in the response to oxidative stress and some isoforms are drug targets in diseases such as cancer, epilepsy and arthritis.
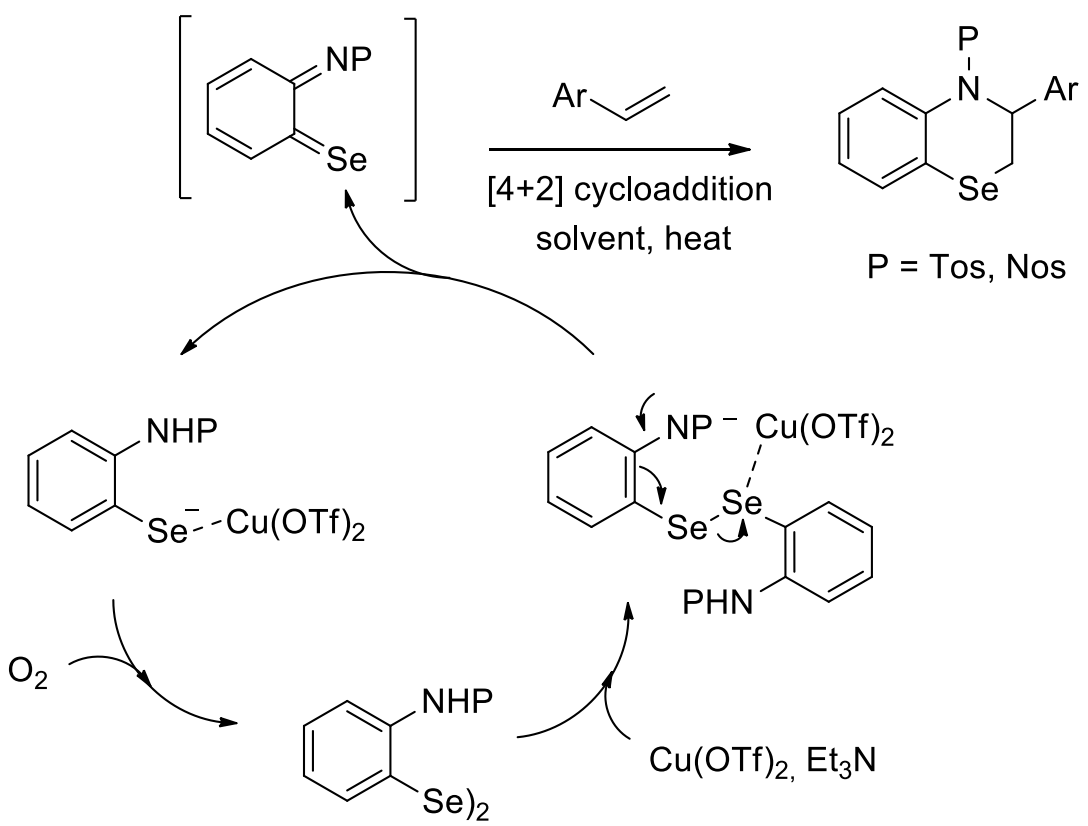

Scheme 27. Synthesis of benzo[b][1,4]selenazines.

\section{Electrophilic Selenium-catalyzed Amination of Alkenes}

Functionalizations of alkenes by domino selenylation/deselenylation sequences using catalytic amounts of diselenides have been the object of intense investigations. ${ }^{4,94-96}$ The availability of organic or inorganic oxidants able to regenerate in situ the active electrophilic selenium species is crucial in these reactions. Recently, catalytic selenofunctionalizations of alkenes for the introduction of nitrogen functional groups have attracted great interest as atom-economic, cost-effective and environmentally friendly alternative to transition metal-catalyzed oxidative aminations of olefins. The poor stability of the nitrogen-containing 
substrates and products under the oxidative conditions required makes this approach particularly challenging. Scheme 28 shows the selenium-catalyzed imidation of alkenes developed by Breder et al. in $2015 .{ }^{97}$ Only 5 mol\% of PhSeSePh and one equivalent of NFSI, as both the oxidant and the nitrogen source, were sufficient to generate allylic or vinylic imides in acceptable to high yields depending on the structure of the starting alkene.

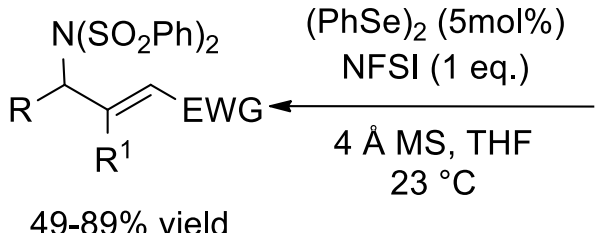

$49-89 \%$ yield

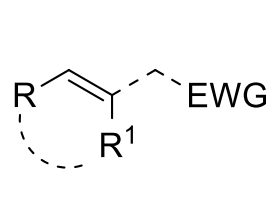

$23^{\circ} \mathrm{C}$
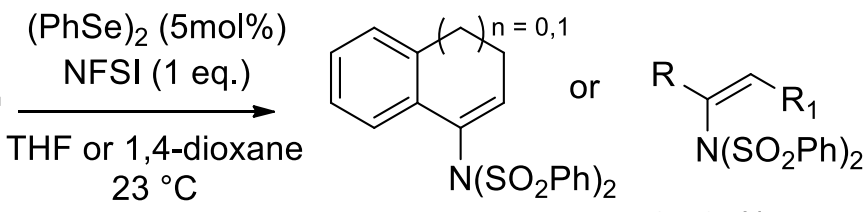

$65-95 \%$ yield

Scheme 28. Selenium-catalyzed allylic or vinylic imidation of alkenes.

The allylic amination was compatible with the presence of a variety of electron-withdrawing groups such as esters, amides, nitriles, ketones, phosphonates, and sulfones. The use of cyclic or linear alkenes gave vinylic imides in good to excellent yields. Such reactions can be reasonably explained by the catalytic cycle reported in Scheme 29. Firstly, the NFSI oxidizes the diphenyl diselenide to form the electrophilic selenium species. Next, the addition to the alkene generates the cationic adduct that undergoes the elimination. The elimination step occurs regioselectively, depending on the structure of the starting alkenes. The fluoride acts as a base and assists the elimination that regenerates the diselenide for the completion of the catalytic cycle.

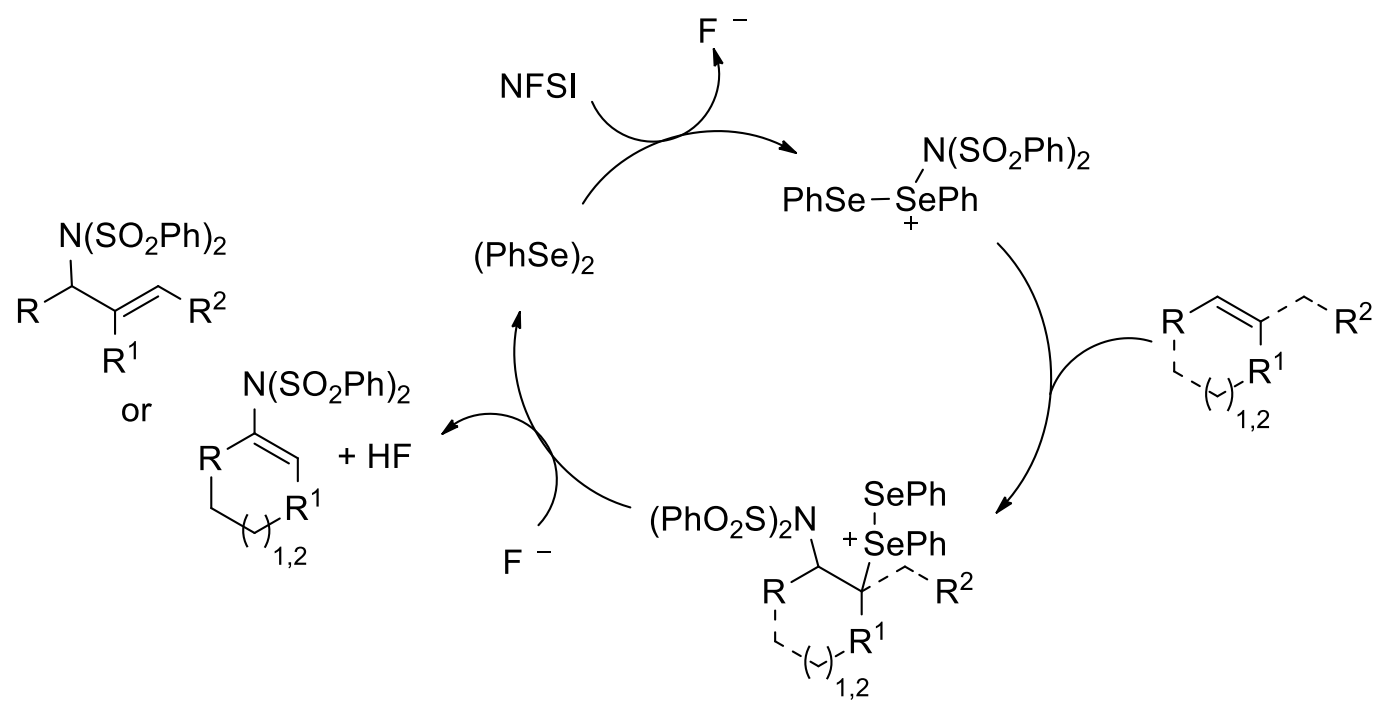

Scheme 29. Catalytic cycle for the allylic and vinylic amination of alkenes.

The first enantioselective variant of the catalytic allylic amination of alkenes recently appeared in the literature. ${ }^{98}$ Four new chiral diselenides derived from an enantiopure diol were rationally designed and tested as catalysts, but in the best case, the product was obtained in 81\% yield with a moderate 75:25 er.

Zhao et al. developed a method for the preparation of allylic 3-aminoalcohols from commercial or easily accessible allylic alcohols by treatment with $5 \mathrm{~mol} \%$ of PhSeSePh and NFSI in the presence of bases (Scheme 30). ${ }^{99}$ The hydroxylic oxygen completely controlled the regioselectivity of the process due to non covalent 
interactions with the selenium cation. Interestingly, the formation of mixtures of amination products were observed when protected alcohols were employed under similar reaction conditions.

Control experiments revealed that the presence of the base is crucial for the success of the reaction, in fact in acidic conditions the initially formed 3-amino allylic alcohol decomposes to the corresponding unsaturated aldehyde. $Z$ aminoalkenes were isolated in good yields and excellent regio- and stereo-selectivity from reactions carried out with 1,2-disubstituted alkenes without the need of any base, but with prolonged reaction times.<smiles>[R]C([R])(O)C=C[I-]</smiles><smiles>[R]C=CC([R])O</smiles>

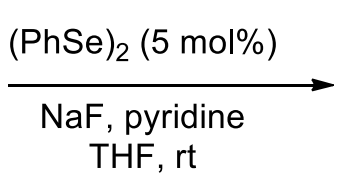<smiles>[R]C([R])(O)C=CNS(=O)(=O)O</smiles>
15 examples $67-95 \%$ yield

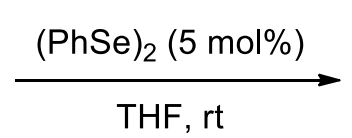<smiles>[R]C(=CC([R])O)[N+](=O)O[Na]</smiles>

4 examples

$71-92 \%$ yield

Scheme 30. Selenium-catalyzed amination of allylic alcohols.

Last year it was demonstrated that not only diselenides, but also phosphine selenides were able to catalyze vinylic aminations of terminal alkenes (Scheme 31). ${ }^{100}$ After careful investigations for the best phosphine ligand, enamines were obtained in high yields and good to excellent $E / Z$ ratio.

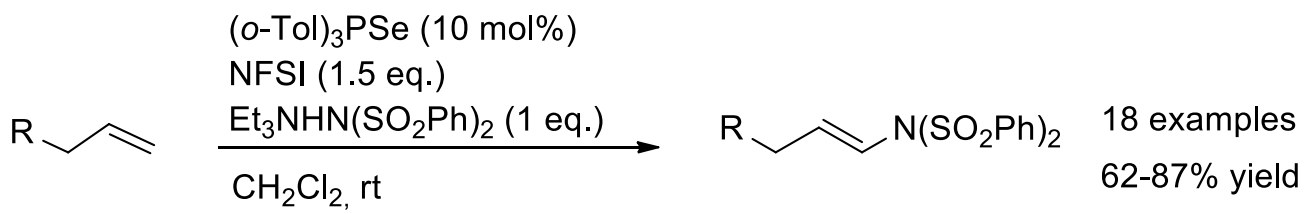

Scheme 31. Vinylic aminations catalyzed by a phosphine selenide.

Catalytic intramolecular vinylic aminations have been also developed using substrates with internal nitrogen nucleophiles for an efficient and practical access to heterocyclic compounds. Breder ${ }^{101}$ and Zhao $^{102}$ groups independently, developed the synthesis of indoles starting from ortho-vinylanilines using catalytic $\mathrm{PhSeSePh}$ and stoichiometric NFSI. The nature of the protecting group plays a key role in this process, since this group modulates the acidity of the $\mathrm{N}-\mathrm{H}$ with effects on the nucleophilicity. In fact, if reactions with substrates protected with tosyl, mesyl, and nosyl groups gave products in good yields, those with carboxamide protected substrates were unsuccessful. The method has a wide scope since different substitution patterns were tolerated on the alkene and aromatic ring. A broad range of functionalized indoles were synthesized and the protocol was also extended to the preparation of azaindoles (Scheme 32). 


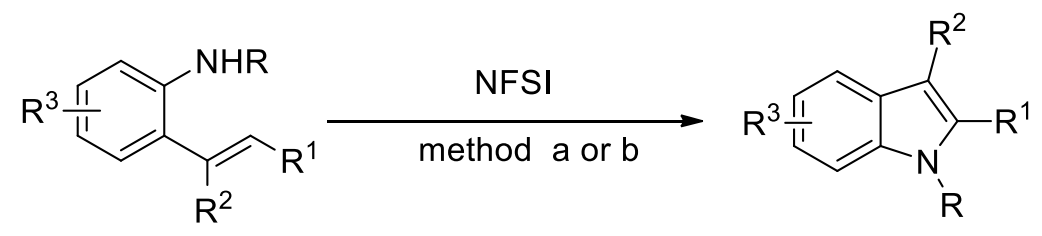

a. PhSeSePh, (2.5 mol\%), $4 \AA \mathrm{MS}$, Toluene, $100^{\circ} \mathrm{C}, 16 \mathrm{~h}$, ref. 101

b. PhSeSePh, (10 mol\%), 1,4-dioxane, $30^{\circ} \mathrm{C}, 18 \mathrm{~h}$, ref. 102

Selected examples:<smiles>Cc1cc2ccccc2n1[13CH3]</smiles><smiles>Cc1cc2ccccc2n1C(C)([O-])[O-]</smiles><smiles>[Y9]n1c(C2CCCCC2)cc2ccccc21</smiles><smiles>[Y5]n1c(-c2ccccc2)cc2ccccc21</smiles>
$97 \%^{\mathrm{a}}\left(89 \%^{\mathrm{b}}\right)$

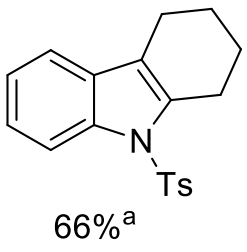<smiles>CCCc1cc2ccccc2n1[AsH2]</smiles>
$\mathrm{MeO}_{2} \mathrm{C}$ $65 \%^{\mathrm{a}}$
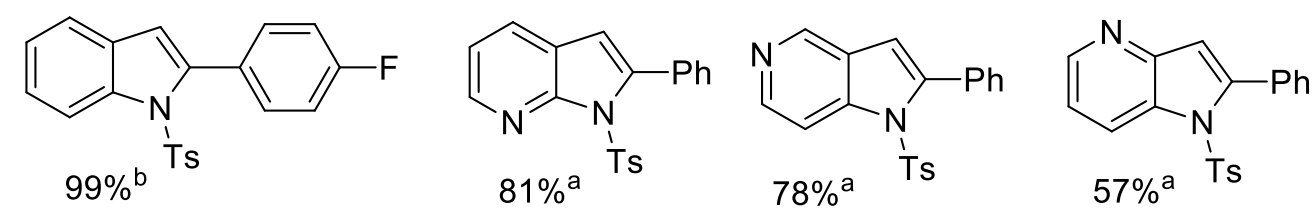

Scheme 32. Selenium-catalyzed synthesis of indoles and azaindoles.

The synthesis of pyrazolo[5,1- $b$ ]quinazolinones has been achieved starting from easily available $(E)$-3-styryl substituted quinazolin-4(3H)-ones and using the same catalytic system in acetonitrile under reflux in the presence of molecular sieves (Scheme 33). ${ }^{103}$ The 2,3-heterocycle-fused quinazolinone core is frequently found in natural products and compounds with pharmacological properties such as antimicrobial and anticancer agents. Several products with broad structural diversity at the aromatic rings have been obtained in good yields. The protocol has been scaled up to gram scale.<smiles>[R]Nn1c(/C=C/[Al])nc2ccccc2c1=O</smiles>

$\mathrm{R}=\mathrm{H}, \mathrm{CH}_{3}, \mathrm{~F}, \mathrm{Cl}, \mathrm{Br}, \mathrm{I}, \mathrm{CF}_{3}$ $\mathrm{R}^{1}=$ Aryl, $\mathrm{Pr}$

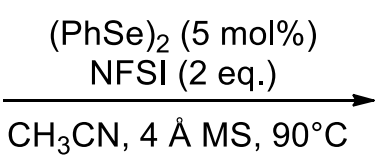

(

$\mathrm{CH}_{3} \mathrm{CN}, 4 \AA \mathrm{MS}, 90^{\circ} \mathrm{C}$ 
Analogously, isoquinoline derivatives were accessible from ortho-styryl substituted benzaldehyde hydrazones or oximes. ${ }^{104}$ Scheme 34 shows a representative example. The formed isoquinolinium imide has been reduced with $\mathrm{NaBH}_{4}$ or converted into a fused pyrazoloisoquinoline by a 1,3-dipolar cyclo addition reaction with 4-ethynylanisole.

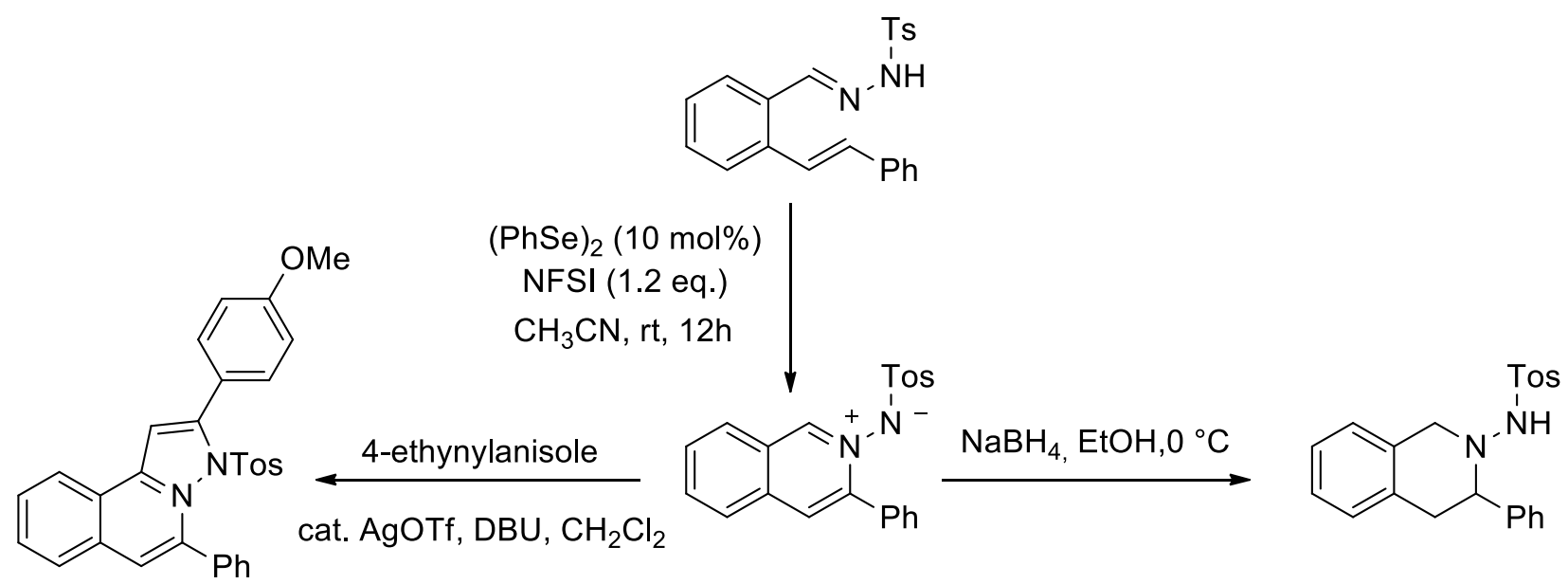

Scheme 34. Selenium-catalyzed synthesis of isoquinoline derivatives.

Catalytic PhSeSePh and fluoropyridinium triflate (FP-OTf) were used in the presence of NaF for the oxidative cyclization of unsaturated sulfonamides. Cyclizations in the exo-mode gave 2-alkenyl-substituted pyrrolidines or piperidines in reasonable to good yields (Scheme 35). ${ }^{105}$ Azepines were obtained when reactions were performed with substoichiometric amounts of the base. An HF-assisted rearrangement of the initially formed pyrrolidines seems to be responsible of the ring expansion.

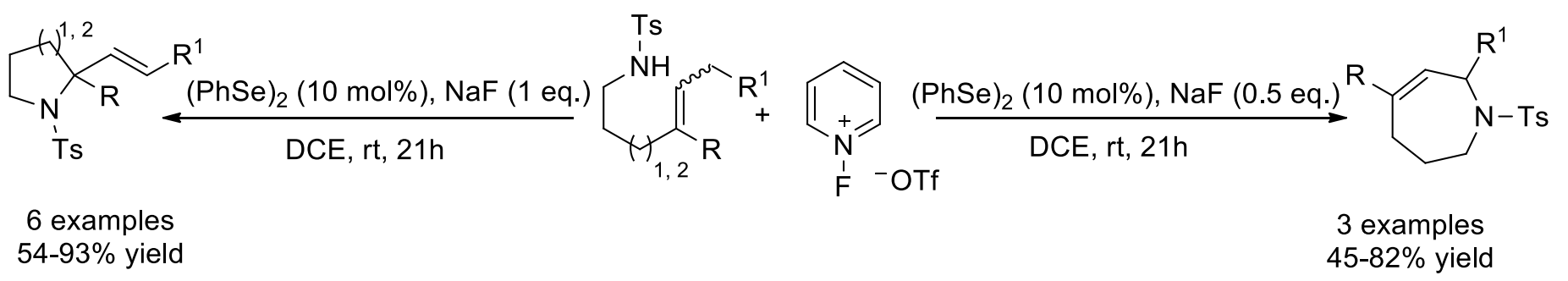

Scheme 35. Selenium-catalyzed synthesis of nitrogen 5-7 membered heterocycles.

Very recently, the catalytic system PhSeSePh and FP-OTf was also employed for the first seleniumcatalyzed amination of dienes with pyridines (Scheme 36). ${ }^{106}$ The reactions, carried out in acetonitrile and tetrahydrofuran with dibenzyl diselenide, gave a variety of pyridinium salts in moderate to good yields and complete C2-selectivity. The method nicely complements Heck-type reactions characterized by selectivity for the C1 position. The new protocol was employed regardless of the steric hindrance not only with aryl, alkyl, and cyclic 1,3-dienes, but also with terpene and styrene derivatives. In most experiments the fluoropyridinium reagent acts not only as the oxidant, but also as the pyridine source. However, the procedure has been adapted to the insertion of other pyridine derivatives suitably added to the reaction mixture. The intramolecular version of the reaction gave intermediates with potential applications in the synthesis of natural products. 


$$
\begin{aligned}
& \mathrm{R}=\mathrm{H} \text {, alkyl } \\
& \mathrm{R}^{1}=\mathrm{R}^{2}=\mathrm{H}, \text { alkyl, } \\
& \operatorname{aryl} \mathrm{R}^{3}=\mathrm{H}, \mathrm{CH}_{3}
\end{aligned}
$$<smiles>[R]C=C(C1=C([R])CC[R]1[R])[n+]1ccccc1</smiles>

32 examples $40-96 \%$ yield

Scheme 36. Selenium-catalyzed pyridination of dienes and alkenes.

Finally a cooperative selenium-iodine catalyzed cyclization of tryptamine derivatives was reported by Ishihara et al. (Scheme 37). ${ }^{107}$ Catalytic amounts of PhSeSePh and $\mathrm{I}_{2}$ in the presence of $\mathrm{N}$-chlorosuccinimide (NCS) gave C3a-chlorohexahydropyrrolo[2,3-b]indoles in good to excellent yields. Such chlorine-containing compounds are useful intermediates in the total synthesis of (-)-Psychotriasine and (-)-5- $N$-Acetylardeemin (Figure 1).

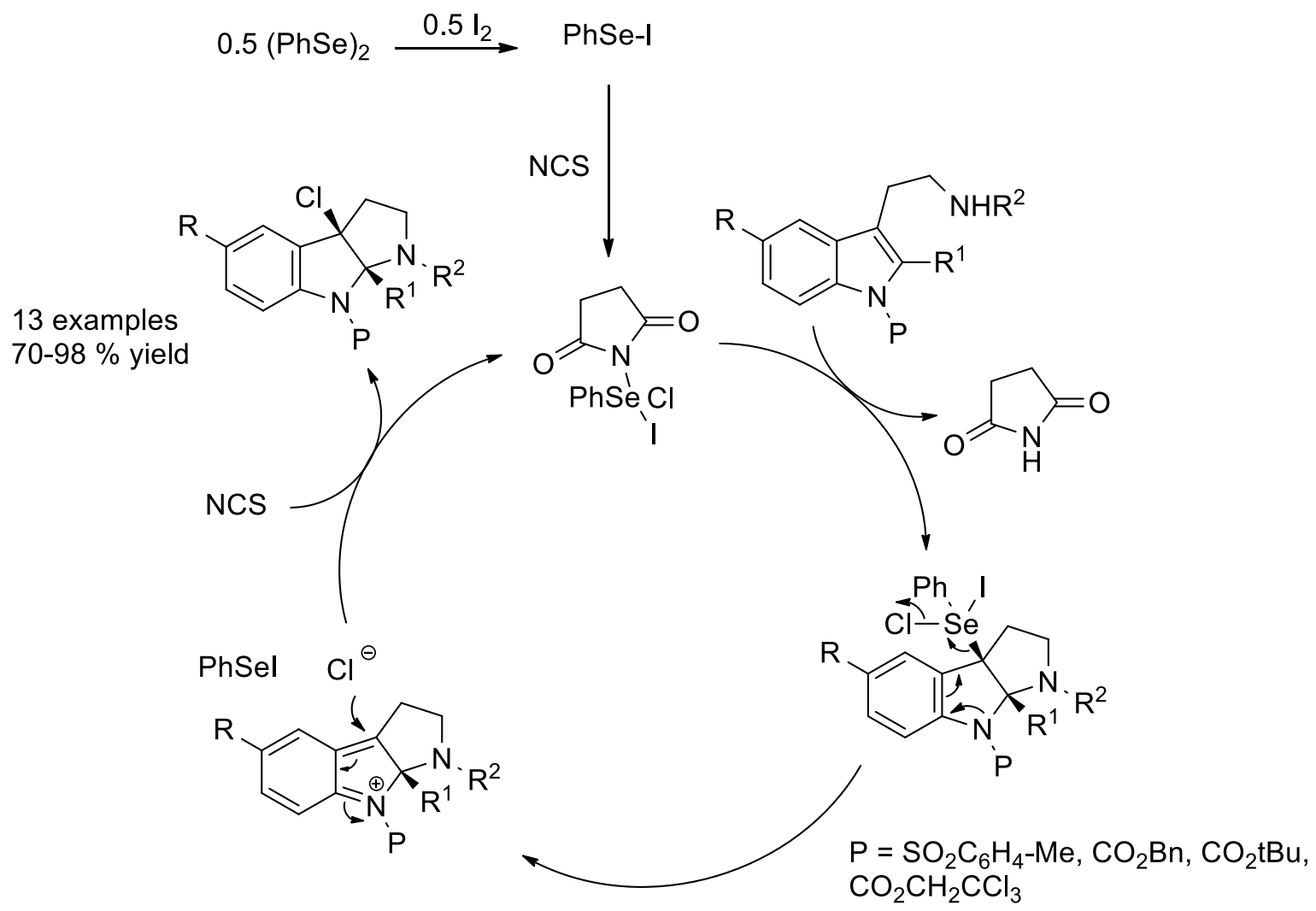

Scheme 37. Chlorocyclization of tryptamine derivatives by selenium-iodine cooperative catalysis. 


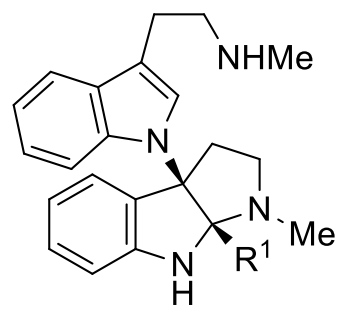

(-)-Psychitriasine

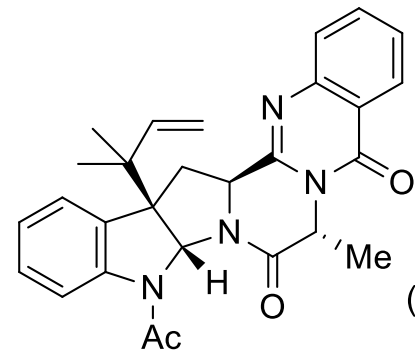

$(-)-5-N-A c e t y l a r d e e m i n$

Figure 1. (-)-Psychotriasine and (-)-5-N-Acetylardeemin.

NMR studies provided evidence of the formation of the Se(IV) derivatives. Authors proposed that the PhSel, initially generated by reaction of the iodine with the diselenide, was further oxidized by NCS to generate the effective selenium electrophile. After the ring closure an iminium ion was formed by deselenylation. The nucleophilic attack of the chloride onto the iminium ion generated the final product.

\section{Conclusions}

In conclusion, in the last years, new methods for the inter- and intramolecular, selenium promoted or catalyzed amination of alkenes or alkynes have been reported. Recent advances refer to the exploration of new nitrogen sources or oxidative systems for reactions featured by broad scope, wide functional group tolerance, high regio-and stereo-selectivity, and mild reaction conditions. A particular attention has been devoted to catalytic methods. However, despite the numerous advances, some challenges remain to be addressed particularly in the development of catalytic enantioselective methods.

\section{Acknowledgements}

Authors thanks Università degli Studi di Perugia, "Fondo per il sostegno della Ricerca di Base 2018, Project "Sviluppo di metodologie innovative per la sintesi efficiente di composti eterociclici, molecole drug-like e intermedi sintetici ad alto valore aggiunto" for the financial support and Regione Umbria for the Postdoctoral Research Fellowship to MP. This work is part of the scientific activity of the international multidisciplinary "SeS Redox and Catalysis" network and National Interuniversities Consortium C.I.N.M.P.I.S.

\section{References}

1. Tiecco, M.; In Topics in Current Chemistry: Organoselenium Chemistry: Modern Developments in Organic Synthesis; Wirth, T. Ed.; Springer-Verlag: Heideberg, 2000; Vol. 208, pp 7-54.

2. Organoselenium Chemistry: A Practical Approach; Back. T. G. Ed.; Oxford University Press: Oxford, 1999.

3. Santi, C.; Santoro, S. In Organoselenium chemistry: synthesis and reactions; Wirth, T. Ed.; Wiley-VCH: Wenheim, 2012; pp 1-51.

4. Wirth, T. Angew. Chem. Int. Ed., 2000, 39, 3740. http://doi.org/10.1002/1521-3773(20001103)39:21<3740::AID-ANIE3740>3.0.CO;2-N 
5. Petragnani, N.; Stefani, H. A.; Valduga C. J. Tetrahedron 2001, 57, 1411.

http://doi.org/10.1016/S0040-4020(00)01033-4

6. Tiecco, M.; Testaferri, L.; Bagnoli, L.; Marini, F.; Santi, C.; Temperini, A.; Scarponi, C.; Sternativo, S.;

Terlizzi, R.; Tomassini, C. Arkivoc, 2006, (vii) 186.

http://doi.org/10.3998/ark.5550190.0007.715

7. Soloshonok, V. A.; Nelson, D. J. Beilstein J. Org. Chem. 2011, 7, 744.

http://doi.org/10.3762/bjoc.7.85

8. Lenardão, E. J.; Santi, C.; Sancineto, L. New Frontiers in Organoselenium Compounds; Springer International Publishing, 2018, pp 99-143.

9. Organoselenium Compounds in Biology and Medicine: Synthesis, Biological and Therapeutic Treatments; Jain, V. K.; Priyadarsini, K. I. Eds; The Royal Society of Chemistry, 2018.

10. Nogueira, C. W.; Zeni, G.; Rocha, J. B. T. Chem. Rev. 2004, 104, 62553. http://doi.org/10.1021/cr0406559

11. Fernandes, A. P.; Gandin, V. Biochim. Biophys. Acta, Gen. Subj. 2015, 1850, 1642. http://doi.org/10.1016/i.bbagen.2014.10.008

12. Pacula, A. J.; Mangiavacchi, F.; Sancineto, L.; Lenardao, E. J.; Scianowski, J.; Santi, C. Curr. Chem. Biol. 2015, 9, 97.

http://doi.org/10.2174/2212796810666160120220725

13. Reich, H. J.; Hondal, R.J. ACS Chem. Biol. 2016, 11, 821.

http://doi.org/10.1021/acschembio.6b00031

14. Barbosa, N. V.; Nogueira, C. W.; Nogara, P. A.; F. de Bem, A.; Aschnerc, M.; Rocha, J. B. T. Metallomics 2017, 9, 1703.

http://doi.org/10.1039/C7MT00083A

15. Toshimitsu, A.; Aoai, T.; Uemura, S.; Okano, M .J. Chem. Soc. Chem. Commun. 1980, 1041. http://doi.org/10.1039/C39800001041

16. Toshimitsu, A.; Aoai T.; Owada, H.; Uemura, S.; Okano, M. J. Org. Chem. 1981, 46, 4727. http://doi.org/10.1021/jo00336a021

17. Hernandez, R.; Leon, E. I.; Salazar, J.; Suarez, E. J. Chem. Soc. Chem. Commun. 1987, 312. http://doi.org/10.1039/C39870000312

18. Tiecco, M.; Testaferri, L.; Santi, C.; Tomassini, C.; Marini, F.; Bagnoli, L.; Temperini, A. Eur. J. Org. Chem. 2000, 3451.

http://doi.org/10.1002/1099-0690(200010)2000:20<3451::AID-EJOC3451>3.0.CO;2-Q

19. Tiecco, M.; Testaferri, L.; Marini, F.; Temperini, A.; Bagnoli, L.; Santi, C. Synth, Commun. 1997, $27,4131$. http://doi.org/10.1080/00397919708005461

20. Tiecco, M.; Testaferri, L.; Temperini, A.; Marini, F.; Bagnoli, L.; Santi, C. Synth, Commun. 1999, $28,1773$. http://doi.org/10.1080/00397919908086165

21. Hassner, A.; Amarasekara, A. S. Tetrahedron Lett. 1987, 28, 5185. http://doi.org/10.1016/S0040-4039(00)95624-7

22. Tiecco, M.; Testaferri, L.; Santi, C.; Tomassini, C.; Santoro, S.; Marini, F.; Bagnoli L.; Temperini, A. Tetrahedron 2007, 63, 12373. http://doi.org/10.1016/j.tet.2007.09.047

23. Riela, S.; Aprile, C.; Gruttadauria, M.; Lo Meo, P.; Noto, R. Molecules 2005, 10, 383. http://doi.org/10.3390/10020383 
24. Tiecco, M.; Testaferri, L.; Santi, C.; Tomassini, C.; Marini, F.; Bagnoli L.; Temperini, A. Angew. Chem. Int. Ed. 2003, 42, 3131.

http://doi.org/10.1002/anie.200351229

25. Tiecco, M.; Testaferri, L.; Santi, C.; Tomassini, C.; Santoro, S.; Marini, F.; Bagnoli L.; Temperini, A.; Costantino F. Eur. J. Org. Chem. 2006, 4867. http://doi.org/10.1002/ejoc.200600517

26. Tingoli, M.; Tiecco, M.; Chianelli, D.; Balducci, R.; Temperini, A. J. Org. Chem. 1991, 56, 6809. http://doi.org/10.1021/jo00024a020

27. Tingoli, M.; Tiecco, M.; Testaferri, L.; Andrenacci, R.; Balducci, R. J. Org. Chem. 1993, $58,6097$. http://doi.org/10.1021/jo00074a042

28. Czernecki, S.; Ayadi, E.; Randriamandimby, D. J. Org. Chem. 1994, 59, 8256. http://doi.org/10.1021/jo00105a051

29. Tang, E.; Wang, W.; Zhao, Y.; Zhang, M.; Dai, X. Org. Lett. 2016, 18, 176. http://doi.org/10.1021/acs.orglett.5b03157

30. Sun, K.; Wang, X.; Lv, Y.; Li, G.; Jiao, H.; Dai, C.; Li, Y.; Zhang, C.; Liu, L. Chem. Commun. 2016, $52,8471$. http://doi.org/10.1039/C6CC04225B

31. Wang, X.; Li, H.; Zhu, M.; Yan, J. RSC Adv. 2017, 7, 15709. http://doi.org/10.1039/C6RA27202A

32. Liu, Y.; Li, C.; Mu, S.; Li, Y.; Feng, R.; Sun, K. Asian J. Org. Chem. 2018, 7, 720. http://doi.org/10.1002/ajoc.201800030

33. Sun, K.; Wang, X.; Zhang, C.; Zhang, S.; Chen, Y.; Jiao, H.; Du, W. Chem.Asian. J. 2017, 12, 713. http://doi.org/10.1002/asia.201700017

34. Sun, L.; Yuan, Y.; Yao, M.; Wang, H.; Wang, D.; Gao, M.; Chen, Y.-H.; Lei, A. Org. Lett. 2019, $21,1297$. http://doi.org/10.1021/acs.orglett.8b03274

35. Perin, G.; Lenardão, E. J.;Jacob, R. G.; Panatieri R. B. Chem. Rev. 2009, 109, 1277. http://doi.org/10.1021/cr8004394

36. Palomba, M.; Bagnoli, L.; Marini, F.; Santi, C.; Sancineto, L. Phosphorus Sulfur Silicon Relat. Elem. 2016, 191, 235. http://doi.org/10.1080/10426507.2015.1067212

37. Palomba, M.; Trappetti, F.; Bagnoli, L.; Santi, C.; Marini, F. Eur. J. Org. Chem. 2018, 3914. http://doi.org/10.1002/ejoc.201800498

38. Marini, F.; Sternativo, S.; Synlett. 2013, 24, 11. http://doi.org/10.1055/s-0032-1317481

39. Zheng, G.; Zhao, J.; Li, Z.; Zhang, Q.; Sun, J.; Sun, H.; Zhang, Q. Chem. Eur. J. 2016, 22, 3513. http://doi.org/10.1002/chem.201504534

40. Wang, Y.-C.; Liu, L.-Q.; Wang, G.-M.; Ouyang, H.; Li, Y.-J. Green Chem. 2018, 20, 604. http://doi.org/10.1039/C7GC03267F

41. Toshimitsu, A.; Terao, K.; Uemura, S. J. Org. Chem. 1986, 51, 1724. http://doi.org/10.1021/jo00360a017

42. Burgess, L. E.; Meyers, A. I. J. Am. Chem. Soc. 1991, 113, 9858. http://doi.org/10.1021/ja00026a026

43. Cooper, M. A.; A. D. Ward Aust. J. Chem. 2011, 64, 1327. http://doi.org/10.1071/CH11073

44. Clive, D. L. J.; Wong, C. K.; Kiel, W. A.; Menchen, S. M. J. Chem. Soc., Chem. Commun. 1978, 379. 
http://doi.org/10.1039/C39780000379

45. Clive, D. L. J.; Farina, V.; Singh, A.; Wong, C. K.; Kiel, W. A.; Menchen, S. M. J. Org. Chem. 1980, 45, 2120. http://doi.org/10.1021/jo01299a019

46. Webb, R. R.; Danishefsky, S. Tetrahedron Lett. 1983, 24, 1357.

http://doi.org/10.1016/S0040-4039(00)81655-X

47. Jones, A. D.; Redfern, A. L.; Knight, D. W.; Morgan, I. R.; Williams, A. C. Tetrahedron 2006, 62, 9247. http://doi.org/10.1016/j.tet.2006.07.018

48. Toshimitsu, A.; Terao, K.; Uemura, S. J. Chem. Soc., Perkin Trans. 1 1986, 1837. http://doi.org/10.1039/P19860001837

49. De Kimpe, N.;Boelens, M. J. Chem. Soc., Chem. Commun. 1993, 916. https://doi.org/10.1039/C39930000916

50. De Smaele, D.; De Kimpe, N. J. Chem. Soc., Chem. Commun. 1995, 2029. http://doi.org/10.1039/C39950002029

51. Grigg, R.; Hadjisoteriou, M.; Kennewell, P.; Markandu, J. J. Chem. Soc., Chem. Commun. 1992, 1537. http://doi.org/10.1039/C39920001537

52. Tiecco, M.; Testaferri, L.; Tingoli, M.; Bagnoli, L.; Marini, F. J. Chem. Soc., Perkin Trans. 1. 1993, 1989. http://doi.org/10.1039/P19930001989

53. Tiecco, M.; Testaferri, L.; Tingoli, M.; Bagnoli, L. J. Chem. Soc., Chem. Commun. 1995, 235. http://doi.org/10.1039/C39950000235

54. Tiecco, M.; Testaferri, L.; Marini, F.; Santi, C.; Bagnoli, L.; Temperini A. Tetrahedron 1997, $53,7311$. http://doi.org/10.1016/S0040-4020(97)00414-6

55. Tiecco, M.; Testaferri, L.; Tingoli, M.; Santi, C.Tetrahedron Lett. 1995, 36, 163. http://doi.org/10.1016/0040-4039(94)02201-L

56. Tiecco, M.; Testaferri, L.; Marini, F. Tetrahedron 1996, 52, 11841. https://doi.org/10.1016/0040-4020(96)00675-8

57. Tiecco, M.; Testaferri, L.; Marini, F. Tetrahedron 1997, 52, 10591. http://doi.org/10.1016/S0040-4020(97)00670-4

58. Tiecco, M.; Testaferri, L.; Marini, F.; Bagnoli, L.; Santi, C.; Temperini, A. Tetrahedron 1997, $53,4441$. http://doi.org/10.1016/S0040-4020(97)00116-6

59. Gilmore, K.; Mohamed, R. K.; Alabugin, I. V. WIREs Comput. Mol. Sci. 2016, 6, 487. http://doi.org/10.1002/wcms.1261

60. Deziel, R.; Malenfant, E. J. Org. Chem. 1995, 60, 4660. https://doi.org/10.1021/jo00119a055

61. Takada, H.; Nishibayashi, Y.; Uemura, S. J. Chem. Soc., Perkin Trans. 1 1999, 1511. http://doi.org/10.1039/A901087D

62. Back, T. G.; Dyer, B. P.; Nan, S. Tetrahedron 1999, 55, 3191.

http://doi.org/10.1016/S0040-4020(98)01133-8

63. Fragale, G.; Wirth, T. Eur. J. Org. Chem. 1998, 1361. http://doi.org/10.1002/(SICI)1099-0690(199807)1998:7<1361::AID-EJOC1361>3.0.CO;2-M

64. Tiecco, M.; Testaferri, L.; Marini, F.; Sternativo, S.; Bagnoli, L.; Santi, C.; Temperini, A. Tetrahedron: Asymm. 2001, 12, 1493. http://doi.org/10.1016/S0957-4166(01)00248-8

65. Tiecco, M.; Testaferri, L.; Marini, F.; Sternativo, S.; Santi, C.; Bagnoli, L.; Temperini, A.Tetrahedron: Asymm. 2001, 12, 3053. 
http://doi.org/10.1016/S0957-4166(01)00543-2

66. Li, X.; He, P.; Zhou, H.-B.; Dong, C. Org. Biomol. Chem. 2018, 16, 2150. http://doi.org/10.1039/C8OB00179K

67. Tiecco, M.; Testaferri, L.; Tingoli, M.; Marini, F. Chem. Soc., Chem. Commun. 1994, 221. http://doi.org/10.1039/C8OB00179K

68. Tiecco, M.; Testaferri, L.; Tingoli, M.; Marini, F. J. Chem. Soc., Chem. Commun. 1995, 237. http://doi.org/10.1039/C39950000237

69. Franck X.; Leleu, S.; Outurquin, F. Tetrahedron Lett. 2010, 51, 4437. http://doi.org/10.1016/i.tetlet.2010.06.087

70. Pannecoucke, X.; Outurquin F.; Paulmier, C. Eur. J. Org. Chem. 2002, 995. http://doi.org/10.1002/1099-0690(200203)2002:6<995::AID-EJOC995>3.0.CO;2-A

71. Outurquin, F.; Pannecoucke, X.; Berthe,B.; Paulmier, C. Eur. J. Org. Chem. 2002, 1007. http://doi.org/10.1002/1099-0690(200203)2002:6<1007::AID-EJOC1007>3.0.CO;2-A

72. Tiecco, M.; Testaferri, L.; Bagnoli, L.; Scarponi, C.; Temperini, A.; Marini, F.; Santi, C. Tetrahedron: Asymm. 2007, 18, 2758.

http://doi.org/10.1016/i.tetasy.2007.11.003

73. Tiecco, M.; Testaferri, L.; Bagnoli, L.; Scarponi, C. Tetrahedron: Asymm. 2008, 19, 2411. http://doi.org/10.1016/i.tetasy.2008.10.006

74. Smit, B. M.; Pavlovic, R. Z. Tetrahedron 2015, 71, 1101. http://doi.org/10.1016/j.tet.2014.12.088

75. Smit, B. M.; Pavlovic, R. Z.; Milenkovic, D. A.; Markovic, Z. S. Beilstein J. Org. Chem. 2015, 11, 1865. http://doi.org/doi:10.3762/bjoc.11.200

76. Marsden, S. P.; Depew, K. M.; Danishefsky, S. J. J. Am. Chem. Soc. 1994, 116, 11143. http://doi.org/10.1021/ja00103a034

77. Depew, K. M.; Marsden, S. P.; Zatorska, D.; Zatorski, A.; Bornmann, W. G.; Danishefsky, S. J. J. Am. Chem. Soc. 1999, 121, 11953.

http://doi.org/10.1021/ja991558d

78. Crich, D.; Huang, X. J. Org. Chem. 1999, 64, 7218. http://doi.org/10.1021/jo991093+

79. Hewitt P. R.; Cleator, E.; Ley, S. V. Org. Biomol. Chem. 2004, 2, 2415. http://doi.org/10.1039/B410180D

80. Ley, S. V.; Cleator, E.; Hewitt, P. R. Org. Biomol. Chem. 2003, 1, 3492. http://doi.org/10.1039/B308288A

81. Lopez C.S.; Perez-Balado, C.; Rodriguez-Grana, P.; de Lera, A. R. Org. Lett. 2008, 10, 77. http://doi.org/10.1021/ol702732i

82. Oelke, A. J.; France, D. J.; Hofmann, T.; Wuitschik, G.; Ley, S. V.; Angew. Chem Int. Ed. 2010, $49,6139$. http://doi.org/10.1002/anie.201002880

83. Shibahara, S.; Matsubara, T.; Takahashi, K.; Ishihara, J.; Hatakeyama, S. Org. Lett. 2011, 13, 4700. http://doi.org/10.1021/ol201912w

84. Wie, Q.; Wang, Y.-Y.; Du, Y.-L.; Gong, L. Z.; Beilstein, J. Org. Chem. 2013, 9, 1559. http://doi.org/doi:10.3762/bjoc.9.177

85. Conner, E. S.; Crocker, K. E.; Fernando, R. G.; Froczek, F. R.; Stanley, G. G.; Ragains, J. R. Org. Lett. 2013, $15,5558$. 
86. Zhang, Q.-B.; Yuan, P.-F.; Kai, L.-L.; Liu, K.; Ban, Y.-L.; Wang, X.-Y.; Wu, L.-Z.; Liu, Q. Org. Lett. 2019, 21, 885.

http://doi.org/10.1021/acs.orglett.8b03738

87. Li, Z.; Hong, L.; Liu, R.; Shen, J.; Zhou, X. Tetrahedron Lett. 2011, 52, 1343.

http://doi.org/10.1016/j.tetlet.2011.01.052

88. Stein, A. L.; Rodrigues Rosario, A.; Zeni, G. Eur. J. Org. Chem. 2015, 5640.

http://doi.org/10.1002/ejoc.201500766

89. Neto, J. S. S. Neto.; Back, D. F.; Zeni, G. Eur. J. Org. Chem. 2015, 1583.

http://doi.org/10.1002/ejoc.201403534

90. Perin, G.; Nobre, P. C.; Mailahn, D. H.; Silva, M. S.; Barcellos, T.; Jacob, R. G.; Lenardao, E. J.; Santi, C.;

Roehrs, J. A. Synthesis 2019, 51, 2293.

http://doi.org/10.1055/s-0037-1611747

91. Viglianisi, C.; Simone, L.; Menichetti, S. Adv. Synth. Catal. 2012, 354, 77.

http://doi.org/10.1002/adsc.201100587

92. Menichetti, S; Capperucci, A., Tanini, D.; Braga, A. L.; Botteselle, G. V. Viglianisi, C. Eur. J. Org. Chem.

2016, 3097.

http://doi.org/10.1002/ejoc.201600351

93. Angeli, A.; Tanini, D.; Viglianisi, C.; Panzanella, L:; Capperucci, A.; Menichetti, S.; Supuran, C. T.

Bioorg.Med. Chem. 2017, 25, 2518.

http://doi.org/10.1016/j.bmc.2017.03.013

94. Shao, L.; Li, Y.; Lu, J.; Jiang, X. Org. Chem. Front. 2019, 6, 2999.

http://doi.org/10.1039/C9Q000620F

95. Freudendahl, D. M. Santoro, S. Shahzad, S. A.; Santi, C. Wirth, T. Angew. Chem. Int. Ed. 2009, $48,8409$. http://doi.org/10.1002/anie.200903893

96. Singh, F. V.; Wirth, T. Catal. Sci. Technol. 2019, 9, 1073.

http://doi.org/10.1039/C8CY02274G

97. Trenner, J.; Depken, C.; Weber, T.; Breder, A. Angew. Chem. Int. Ed. 2013, 52, 8952.

http://doi.org/10.1002/anie.201303662

98. Kratzschmar, F.; Ortgies, S.; Willing, R. Y. N.; Breder, A. Catalysts 2019, 9, 153.

http://doi.org/10.3390/catal9020153

99. Deng, Z.; Wei, J.; Liao, L.; Huang, H.; Zhao, X. Org. Lett. 2015, 17, 1834.

http://doi.org/10.1021/acs.orglett.5b00213

100. Zheng, T.; Tabor, J. R.; Stein, Z. L.; Michael, F. E. Org. Lett. 2018, 20, 6975.

http://doi.org/10.1021/acs.orglett.8b03159

101. Ortgies, S.; Breder, A. Org. Lett. 2015, 17, 2748.

http://doi.org/10.1021/acs.orglett.5b01156

102. Zhang, X.; Guo, R.; Zhao, X. Org. Chem Front. 2015, 2, 1334.

http://doi.org/10.1039/C5Q000179J

103. Zhang, Y.; Shao, Y.; Gong, J.; Zhu, J.; Cheng, T.; Chen, J. J. Org. Chem. 2019, 84, 2798.

http://doi.org/10.1021/acs.joc.8b03179

104. Li, H.; Liao, L.; Zhao, X. Synlett. 2019, 30, 1688.

http://doi.org/10.1055/s-0039-1690103

105. Guo, R.; Huang, J.; Huang, H.; Zhao, X. Org. Lett. 2016, 18, 504.

http://doi.org/10.1021/acs.orglett.5b03543 
106. Liao, L.; Guo, R.; Zhao, X. Angew. Chem. Int. Ed. 2017, 56, 3201. http://doi.org/10.1002/anie.201610657

107. Horibe, T.; Ohmura, S.; Ishihara, K. Org. Lett. 2017, 19, 5525. http://doi.org/10.1021/acs.orglett.7b02613

\section{Authors' Biographies}

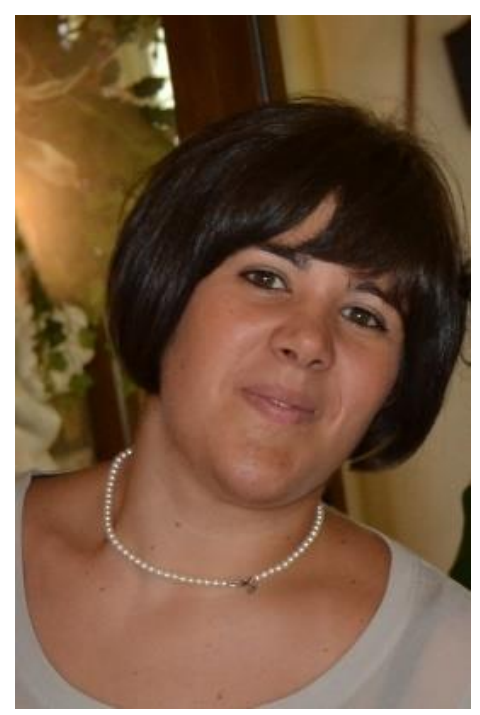

Martina Palomba completed her master's degree in Pharmaceutical Chemistry and Technology at the University of Perugia in 2014. She obtained her PhD in 2018 with the doctoral thesis titled "Organoselenium chemistry in multiple bond-forming reactions and in the synthesis of drug-like molecules" (Supervisors: Prof. Francesca Marini and prof. Luana Bagnoli). During her doctoral studies, in 2017, she spent a research period as visiting student in the group of prof. Alexander Breder at the University of Göttingen. She is currently a postdoctoral research fellow at the University of Perugia.

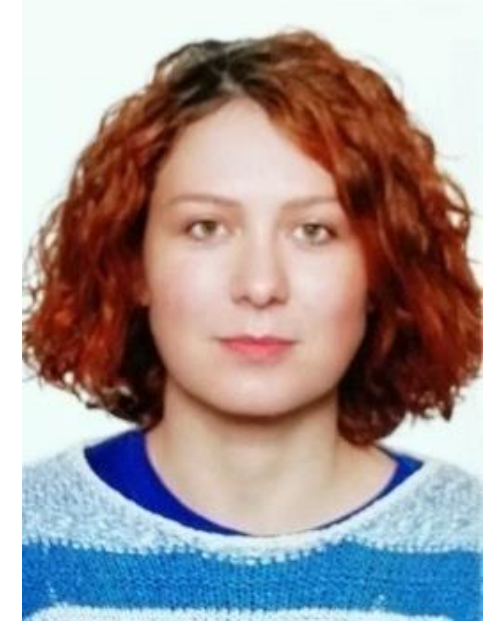

Francesca Mangiavacchi obtained her M.Sc. degree in Pharmaceutical Chemistry and Technology at the University of Perugia in 2016. She received a research fellowship by L'Oreal Paris on the "Synthesis of new redox catalyst and study of their interaction with biological structure" and a research fellowship by Consorzio Interuniversitario Nazionale Metodologie e Processilnnovativi di Sintesi (C.I.N.M.P.I.S.) on the "Synthesis of organoseleno compounds as potential agents in the inflammatory process and bacterial infection of cystic 
fibrosis". She is currently involved, as a PhD student, in the synthesis of organoseleno compounds and in the investigation of their redox mechanisms. In 2019, she spent a research period as visiting student in the group of Prof. Michael J. Davies at the University of Copenhagen.

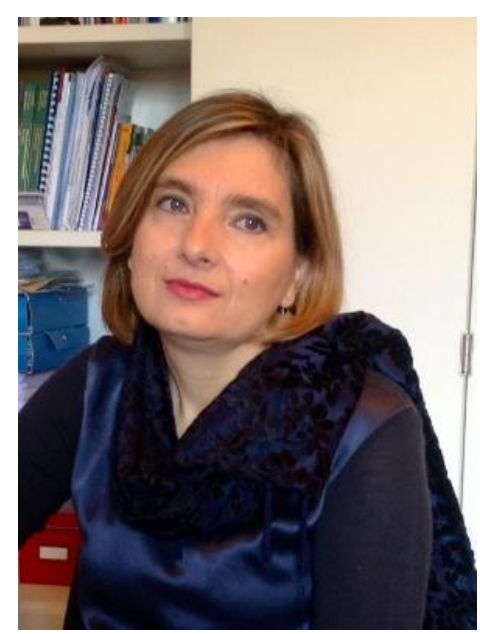

Francesca Marini obtained her M.Sc. degree with honors in Pharmaceutical Chemistry and Technology from the University of Perugia in 1990. After a research fellowship of Mediolanum Farmaceutici S.p.A. on the "Synthesis of Heterocyclic Derivatives of Biological Interest", she received in 1994 the PhD in Chemical Sciences under the Supervision of Prof. Marcello Tiecco with the doctoral thesis "Cyclization reactions promoted by organoselenium compounds. New syntheses of heterocyclic compounds." In the same year she became Assistant Professor at the University of Perugia and from 2006 she is Associate Professor at the same University. Her main scientific interests concern the use of organoselenium reagents in the development of new synthetic methodologies. 